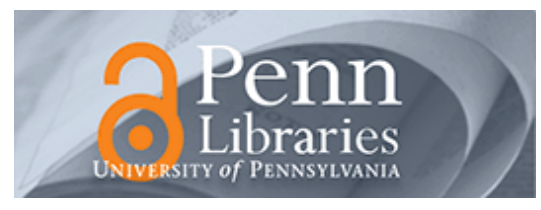

University of Pennsylvania

ScholarlyCommons

Real Estate Papers

Wharton Faculty Research

6-2013

\title{
Pop Internationalism: Has Half a Century of World Music Trade Displaced Local Culture?
}

\author{
Fernando V. Ferreira \\ University of Pennsylvania \\ Joel Waldfogel \\ University of Pennsylvania
}

Follow this and additional works at: https://repository.upenn.edu/real-estate_papers

Part of the International and Intercultural Communication Commons, Music Commons, Other Communication Commons, and the Other Languages, Societies, and Cultures Commons

\section{Recommended Citation}

Ferreira, F. V., \& Waldfogel, J. (2013). Pop Internationalism: Has Half a Century of World Music Trade Displaced Local Culture?. The Economic Journal, 123 (569), 634-664. http://dx.doi.org/DOI: 10.1111/ ecoj.12003

This paper is posted at ScholarlyCommons. https://repository.upenn.edu/real-estate_papers/37

For more information, please contact repository@pobox.upenn.edu. 


\title{
Pop Internationalism: Has Half a Century of World Music Trade Displaced Local Culture?
}

\author{
Abstract \\ Advances in communication technologies have increased the availability of cultural goods across \\ borders, raising concerns that cultural products from large economies will displace those in smaller \\ economies. This article provides stylised facts about global music consumption and trade since 1960 \\ using a unique data on popular music charts corresponding to over $98 \%$ of the global music market. \\ Contrary to growing fears about large-country dominance, our gravity estimates show a substantial bias \\ towards domestic music that has, perhaps surprisingly, increased in the past decade. Moreover, we find \\ no evidence that new communications channels reduce the consumption of domestic music.

\section{Disciplines} \\ International and Intercultural Communication | Music | Other Communication | Other Languages, \\ Societies, and Cultures
}


NBER WORKING PAPER SERIES

POP INTERNATIONALISM:

HAS A HALF CENTURY OF WORLD MUSIC TRADE DISPLACED LOCAL CULTURE?

\author{
Fernando Ferreira \\ Joel Waldfogel \\ Working Paper 15964 \\ http://www.nber.org/papers/w15964
}

NATIONAL BUREAU OF ECONOMIC RESEARCH
1050 Massachusetts Avenue
Cambridge, MA 02138

May 2010

We thank the Wharton Global Initiatives Research Program for funding. Fernando Ferreira would like to thank the Research Sponsor Program of the Zell/Lurie Real Estate Center at Wharton for financial support. Matthew Berg, David Katzianer, Nikhil Bhargava, Eun Young Choi, and Alejandro Jerez provided tireless research assistance. All errors are our own. The views expressed herein are those of the authors and do not necessarily reflect the views of the National Bureau of Economic Research.

NBER working papers are circulated for discussion and comment purposes. They have not been peerreviewed or been subject to the review by the NBER Board of Directors that accompanies official NBER publications.

(C) 2010 by Fernando Ferreira and Joel Waldfogel. All rights reserved. Short sections of text, not to exceed two paragraphs, may be quoted without explicit permission provided that full credit, including (C) notice, is given to the source. 
Pop Internationalism: Has A Half Century of World Music Trade Displaced Local Culture?

Fernando Ferreira and Joel Waldfogel

NBER Working Paper No. 15964

May 2010

JEL No. F13,L82

\begin{abstract}
$\underline{\text { ABSTRACT }}$
Advances in communication technologies over the past half century have made the cultural goods of one country more readily available to consumers in another, raising concerns that cultural products from large economies - in particular the US - will displace the indigenous cultural products of smaller economies. In this paper we provide stylized facts about the global music consumption and trade since 1960, using a unique data on popular music charts from 22 countries, corresponding to over $98 \%$ of the global music market. We find that trade volumes are higher between countries that are geographically closer and between those that share a language. Contrary to growing fears about largecountry dominance, trade shares are roughly proportional to country GDP shares; and relative to GDP, the US music share is substantially below the shares of other smaller countries. We find a substantial bias toward domestic music which has, perhaps surprisingly, increased sharply in the past decade. We find no evidence that new communications channels - such as the growth of country-specific MTV channels and Internet penetration - reduce the consumption of domestic music. National policies aimed at preventing the death of local culture, such as radio airplay quotas, may explain part of the increasing consumption of local music.
\end{abstract}

\author{
Fernando Ferreira \\ The Wharton School \\ University of Pennsylvania \\ 1461 Steinberg - Dietrich Hall \\ 3620 Locust Walk \\ Philadelphia, PA 19104-6302 \\ and NBER \\ fferreir@wharton.upenn.edu \\ Joel Waldfogel \\ Business and Public Policy \\ University of Pennsylvania, Wharton School \\ 1400 Steinberg Hall-Dietrich Hall \\ Philadelphia, PA 19104-6372 \\ and NBER \\ waldfogj@wharton.upenn.edu
}




\section{Introduction}

Advances in communication technologies over the past half century have made the cultural goods of one country more readily available to consumers in another. While lower trade costs are generally good news for consumers - they make a wider range of products available to more people - reduced transaction costs in cultural goods are greeted with much less enthusiasm. A large group outside economics is concerned with possible negative effects of cultural products from distant and large economies, particularly the US, on the local cultural products of smaller economies.

The French have taken the rhetorical lead in exclaiming the American threat to local culture. During the Uruguay Round of trade negotiations in 1993, Jacques Toubon, the French Minister of Culture said, "We must not let our souls be asphyxiated, our eyes blinded, our businesses enslaved. We want to breathe freely - breathe the air that is ours, the air that has nourished the culture of the world, and that, tomorrow, is in danger of being lost to humanity. .. . Let us mobilize for this battle of survival.”1 Then-president François Mitterrand echoed similar sentiments: "Let us be on guard. If the spirit of Europe is no longer menaced by the great totalitarian machines that we have known how to resist, it may be more insidiously threatened by new masters - economisme, mercantilism, the power of money, and to some extent, technology. ... What is at issue is the cultural identity of nations, the right of each people to its own culture, the freedom to create and choose one's images. . . A society that relinquishes to others its means of representation, is an enslaved society."2

The US dominance in the world movie industry provides the main fuel for these concerns. Hollywood movies accounted for 64 percent of revenue across the 15 countries of the EU in 2001 (Eurostat, 2003; Waterman, 2005). While not as large as the movie industry, the US recorded music industry is nevertheless substantial. The combined 2001 value of the recorded music industry in the US and Europe (24 billion euros) exceeds theatrical box office (15.3 billion) but not combined box office and DVD sales/rentals (56.2 billion euros). ${ }^{3}$ Fears of American dominance in music are not entirely unfounded: from 2001 through 2007, 31 artists have appeared simultaneously on at least 18 countries' charts in at least one year. Twenty three

\footnotetext{
${ }^{1}$ Quoted in McMahon, Darrin. "Echoes of a Recent Past: Contemporary French Anti-Americanism in Historical and Cultural Perspective.” International Security Studies at Yale University, January 1995

(http://www.ciaonet.org/wps/mcd01/ ).

${ }^{2}$ From McMahon (1995).

3 These figures are from European Commission (2003).
} 
of these artists - Avril Lavigne, Backstreet Boys, Beyoncé, Black Eyed Peas, Britney Spears, Christina Aguilera, Destiny's Child, Eminem, Enrique Iglesias, Evanescense, Faith Hill, Gnarls Barkley, Gwen Stefani, Jennifer Lopez, Justin Timberlake, Madonna, Mariah Carey, Outkast, P!Nk, Red Hot Chili Peppers, Rihanna, Usher, and Vanessa Carlton - are American. ${ }^{4}$ See Table 1.

While it has become easier for the world's consumers to get access to US music, at the same time it may also have become easier for the world's music producers to get access to the US - and other - markets (Cowan, 2002). The remaining eight artists appearing on charts around the world are from a variety of countries of varying sizes: Nelly Furtado (Canada), Kylie Minogue (Australia), Las Ketchup (Spain), Shaggy (Jamaica), Shakira (Colombia), T.A.T.U. (Russia), Dido and Robbie Williams (United Kingdom). So it’s possible that in a connected world, small-country artists could find new export audiences. As the examples above suggest, globalization could either promote or diminish large-economy dominance in cultural products.

The debate matters for contemporary public policy. Despite a general trend toward free trade negotiated under successive international agreements, cultural goods have had longstanding exceptions. The first GATT agreement in 1947 allowed European countries to place import quotas on American films and, moreover, allowed European countries to undertake policies to “protect national treasures.” At French insistence - and to Hollywood’s dismay - audiovisual products were allowed a “cultural exception” under the Uruguay Round of the General Agreement on Trade in Services (GATS), allowing European countries to maintain import quotas and subsidies to domestic cultural production. ${ }^{5}$ Europe's commitment to policies promoting local culture has been reaffirmed by its 2006 ratification of the UNESCO Convention on Cultural Diversity, which seeks "to protect and promote the diversity of cultural expressions" and which reaffirms "the sovereign rights of States to maintain, adopt and implement policies and measures that they deem appropriate for the protection and promotion of the diversity of

\footnotetext{
${ }^{4}$ Our definition of nationality is based on three criteria, in order: place of first recorded album, country of origin, and most popular in a given country. Avril Lavigne, Enrique Iglesias, and Rihanna, for example, were born in Canada, Spain and Barbados, respectively, but recorded their first albums in the United States. Our results are unchanged when using the country of origin as our unique measure of nationality.

${ }^{5}$ See Grasstek (2005) and Roger Cohen, "Europeans Back French Curbs on U.S. Movies,” New York Times, December 12, 1993.
} 
cultural expressions on their territory." ${ }^{\prime 6}$ Most European countries subsidize their domestic audiovisual sectors, ${ }^{7}$ and some regulate music as well. Four countries in our sample - France, Canada, New Zealand, and Australia - impose domestic radio airplay quotas to promote domestic musical artists.

There are large theoretical and empirical literatures on patterns of bilateral trade in goods. ${ }^{8}$ While scholars note the relative paucity of research on services - and have taken steps to correct it (see Reinsdorf and Slaughter, 2009) - lack of reliable data is a major obstacle, especially for cultural goods. Few studies document trade in cultural services (see Disdier, et. al (2010) and Hanson and Xiang (2008)). ${ }^{9}$

The goal of this project is to provide stylized facts about the patterns of trade and consumption of popular music since 1960. We use novel data based on singles charts covering, for example, the weekly top 40 songs, from as many as 22 countries over past half century (Argentina, Austria, Australia, Belgium, Brazil, Canada, Chile, Denmark, Finland, France, Germany, Italy, Japan, the Netherlands, New Zealand, Norway, Portugal, Spain, Sweden, Switzerland, the UK, and the US). Music consumption in these 22 countries corresponded to over $98 \%$ of the recorded music market in $2003 .{ }^{10}$ The dataset includes 1,202,554 chart entries covering 68,283 songs and 23,377 artists. By employing the national origin of each of the artists, we can determine the penetration of each national repertoire into each importing country. In short, we can ask who buys whose music? What roles do language and geography play in trade flows? Because we observe a measure of sales of each repertoire in each market - and not just

\footnotetext{
${ }^{6}$ See http://portal.unesco.org/culture/en/ev.phpURL ID $=33232 \&$ URL DO=DO TOPIC\&URL SECTION=201.html\#I for a description of the terms of the UNESCO convention, accessed February 6, 2010. See http://ec.europa.eu/culture/portal/action/diversity/unesco_en.htm, accessed February 6, 2010, for announcement of Europe's ratification of the UNESCO convention.

${ }^{7}$ The Television without Frontiers directive, now called the Audiovisual Media Services Directive, "requires broadcasters to reserve a majority proportion of their transmission time, excluding the time appointed to news, sports events, games, advertising, teletext services and teleshopping, for European works.” See http://ec.europa.eu/avpolicy/reg/tvwf/promotion/index_en.htm.

${ }^{8}$ Krugman (1979), Anderson (1979), and Krugman (1980) provide prominent theoretical contributions. See, for example, Leamer and Levinsohn (1995) or Disdier and Head (2006) for introductions to empirics on trade and bilateral trade patterns in particular.

${ }^{9}$ Section II discusses the trade theory in more detail, in addition to the relevant empirical studies of trade in cultural goods.

${ }^{10}$ The recorded music industry generated roughly $\$ 34$ billion in annual revenues in 2003, and according to the International Federation of the Phonograph Industry (IFPI) our sample of 22 countries accounted for $\$ 33.4$ billion in revenues, or nearly all of the world's recorded music revenue for that year.
} 
international trade - we can also examine the extent of home bias in consumption of music. And, finally, how have all of these changed over time during a period when technological change has held the promise of making trade - particularly trade in digitally reproducible services frictionless?

Despite widespread fears about American dominance, we find that music trade is roughly proportional to countries' GDPs and that several smaller countries, such as Sweden, have a larger proportional share of trade than the United States. Trade in music bears some similarities to the trade of physical goods: shorter distances and sharing a common language promote higher trade volumes between countries, and those relationships have been relatively stable over the last 50 years. We also find a large bias toward domestic consumption of music which has, perhaps surprisingly, increased in the past two decades: the share of consumption worldwide that originates from domestic artists increased from less than 50\% during the 1980's to almost 70\% in 2007. This increased home bias is robust to a number of specifications, from descriptive analysis to gravity equations.

What factors explain the increasing consumption of domestic music? We first ask whether the lower trade costs resulting from new communication channels - such as MTV and the Internet - help displace local production and consumption of music. We find that increased home bias is positively associated with the increase in local MTV channels and Internet penetration. Second, we examine the role of protectionist policies to spur the popularity of locally produced music. We document the importance of this mechanism by estimating the impact of quotas on domestic radio airplay on the share of domestic consumption.

A few caveats accompany these results. First, American music may indirectly affect the type or genre of music produced and consumed by other countries, i.e., French artists may produce rock \& roll in France. We explore this issue with a limited analysis of genre data. Second, smaller countries that have benefited the most from globalization, such as Sweden, may actually produce and export music in English - which is arguably not indigenously Swedish. Finally, while we cannot determine whether our results apply to developing countries such as China, India, and African countries, our data from Brazil show negligible effects of fifty years of globalization on its music trade and consumption patterns. 
Overall, our estimates indicate that fears of cultural globalization seem misplaced, at least with respect to the music market. Some smaller countries actually benefit substantially in this global market, as they are able to achieve market shares that are sometimes two or three times larger than the relative sizes of their economies. Moreover, new technologies that lower trade costs do not appear to have a destructive effect on local production and consumption of music. Still, national policies that stimulate the production of local music appear effective in stimulating demand for domestic products.

The paper proceeds in six sections after the introduction. Section II reviews the literature and provides theoretical background that motivates the questions we ask. Section III describes the data used in the study. Section IV reports results, in three parts. First, we offer descriptive characterization of national repertoires' market shares, home bias, and the spatial pattern of contemporary music trade. Second, we characterize changes in national market shares and trade patterns over the past half century. Third, we examine these questions via empirical gravity models of the sort employed in the trade literature. Section $\mathrm{V}$ then turns to a discussion of our results. We present evidence supportive of the view that the recent growth in home bias is related to changes in technology, such as MTV and Internet, and also due to changes in national policy, such as the implementation of radio quotas. Section VI presents additional robustness tests of our main estimates, and Section VII concludes the paper.

\section{Background}

\section{II.a. Theory}

Music, along with other reproducible cultural products such as movies, is a differentiated product that is produced subject to increasing returns. The costs of recorded music, particularly as distribution technology has advanced, are almost entirely fixed. The motivations for trade in such products are outlined in Krugman (1979): consumers like variety, and trade makes a wider variety of products available to consumers in each country. Because of increasing returns, each variety is produced in only one country. It is not clear which product gets produced where, but trade is balanced in the sense that the representative consumer's product bundle has proportional representation from each producing country (according to the respective countries' sizes). This 
simple model, with identical tastes and capabilities throughout the world gives rise to a simple frictionless gravity equation: artists from each country will have a world music market share equal to their countries' share of the world economy/labor force.

The "gravity model," in which trade between countries $i$ and $j$ is related to the market sizes of the two countries, can be derived from a variety of trade theories. The starkest version of this model, adapting Anderson (1979) to our context, is

(1) $M_{i j}=\frac{Y_{i} Y_{j}}{Y}$

where $M_{i j}$ is the sales of repertoire from $i$ in country $j, Y_{i}$ is the GDP of country $i$, and $Y$ is the world GDP. This version of the model has a single good, no transport costs, and identical preferences across all countries. It can be restated, intuitively, to say that the market share of repertoire from country $i$ among overall sales in country $j$ equals country $i$ 's share of the world economy:

(2) $\frac{M_{i j}}{Y_{j}}=\frac{Y_{i}}{Y}$.

Although this "proportional” model is not meant as a realistic prediction, it does provide a benchmark for beginning the analysis. The empirical literature on trade, discussed below, does so with an eye toward deviations from this simple proportional model due to supply factors, including trade costs associated with distance between countries, as well demand factors relating to differences in preferences across countries, including home bias in consumption, and effects of linguistic similarity on consumption.

Industrial economics also provides a framework for thinking about possible dominance of the world market by large-market producers. As Sutton (1991) argues, when product quality is determined by investments in fixed costs - as is clearly the case for media products - and when consumers agree on what constitutes quality, so that competition is vertical, then market enlargement need not lead to fragmentation. ${ }^{11}$ The opening of trade is a form of market enlargement, explicitly so if the tastes of the trading countries are identical. With a larger

\footnotetext{
${ }^{11}$ Berry and Waldfogel (forthcoming) draw on Sutton (1991) to interpret the relationship between market size and concentration in US newspaper markets.
} 
market, a firm can profitably maintain market share by larger investments in quality, maintaining market share even as market size increases. Thus when trade opens among a group of countries, it is possible that some artists or some national repertoires can invest in quality (for example through music videos or other promotional activity) and be more appealing to consumers around the world.

While some features of media products - heavy reliance on fixed costs - correspond well to the Sutton setup, others may not. First, while competition may indeed have some vertical aspects, it is also clear that music products are horizontally differentiated (think, for example, of different genres of popular music, including country, rap, and pop). Moreover, different countries quite possibly have different taste distributions. So while Sutton provides a way to organize thinking about how the worldwide availability of, say, Britney Spears could result in her domination of the world market for popular music, the framework also provides ways to rationalize continued fragmentation and continued attachment to domestic products in the face of globalization, or greater trade possibilities.

The foregoing section serves to organize the descriptive analysis that follows, in which we seek to examine two questions:

1) Who trades with whom in the popular music market? Is trade proportional, as in frictionless gravity models, or do artists from particular countries play a disproportionate share?

2) How have patterns of trade changed over the past half century as "transport costs" of various sorts (literal, based on cultural distance) have declined? Has globalization promoted increased or decreased dominance by artists from large countries?

\section{II.b. Relevant Literatures}

This study is also directly related to three existing literatures in economics: 1) the (small) empirical literature on trade in cultural products, especially movies; 2) the empirical literature on the effect of distant media products on local behaviors; and 3) the normative theoretical literature on the desirability of free trade in cultural products. We describe these in turn. 
Despite the interest in cultural trade, there is relatively little empirical work in economics about the subject. Cowan (2002), critical of naïve anti-globalizationists, provides anecdotal evidence that globalization allows promotion of small-country cultures. Disdier et al (2010) estimate empirical gravity models on bilateral trade flows, 1988-2004, in cultural goods (including books, newspapers, recorded media, visual arts, and audio visual materials). They find that distance reduces trade flows and that common language and colonial links raise trade. They rely on the UN's COMTRADE database. While perhaps the best data source available on trade in cultural products, it nevertheless has some shortcomings, such as incomplete coverage of transactions among subsidiaries of multinational corporations (see UNESCO, 2005). Because of the shortcomings in conventional trade data, Hanson and Xiang (2008) use film industry sources to assemble a novel dataset covering foreign box office receipts for Hollywood movies, allowing them to calculate their own trade statistics. They find that they are more popular in countries with similar languages and in countries with smaller economies. US movies are less popular in countries that, all things equal, are further away. ${ }^{12}$ Blum and Goldfarb (2006) study US Internet users' visits to foreign sites and document a surprisingly strong distance effect for information consumed digitally over the Internet. ${ }^{13}$

Another relevant strand of work examines the effect of distant, as opposed to local, media products on behaviors. Research in this vein includes Oster and Jensen's (2007) work on the spread of cable television to remote regions of India and concomitant effects on treatment of local women, research on the effect of the spread of national newspapers on the targeting of local newspaper products (George and Waldfogel 2006), and work on the effect of local media products on voter turnout (Oberholzer, Gee, and Waldfogel 2009). Disdier, Head and Mayer (2010) provide evidence that the introduction of foreign television in France causes substantial changes in baby naming, away from traditional French names such as Sebastien drawn from saint names and toward American names such as “Dylan” or "Brenda.” This is evidence that trade in cultural products - in this case television programming - affects a symbolically important local behavior, how children are named.

\footnotetext{
${ }^{12}$ See also Marvasti and Canterbery (2005).

${ }^{13}$ Felbermayr and Toubal (2010) find that bilateral scores in the Eurovision Song Contest, a measure of crosscultural affinity, are correlated with trade flows.
} 
Finally, economists have recently developed theoretical models in which the effect of trade in cultural goods has ambiguous benefit. Francois and Ypersele (2002) develop a model in which domestic consumers value both a global ("Hollywood”) and a local good. Because of fixed costs, the local good can be driven out by trade, so depending on the distribution of tastes, it's possible for a tariff on foreign movies to be welfare-improving. Janeba (2003) also models network externalities for cultural goods, and finds that trade can be welfare improving if the world is culturally homogeneous but may not be if countries are culturally diverse. Bala and Van Long (2005) develop an evolutionary model in which trade can cause the preferences of a large country to take over the preferences of a smaller country. Such an effect can, in turn, justify restrictions on cultural imports into smaller countries.

All of these models suggest potential problems with displacement of local products. But the concerns they raise are relevant only if the products of some countries actually drive out the products of others, a question this paper seeks to address.

\section{Data}

The data for this study are based on chart entries from 22 countries, from 1960 through 2007. Charts are collected from disparate sources, so they differ in frequency and length (number of positions). For many countries and years, we have weekly top 20 charts. For others, we have the weekly top 100 . We have weekly charts for 10 of the countries over at least some years. For two countries - Australia and Brazil - we have only annual top 100 charts. The data include a total of 1,222,384 chart entries. ${ }^{14}$ We transform these sources of disparate lengths and

\footnotetext{
${ }^{14}$ We obtained the chart data from a variety of online sources (links accessed on December 2009): Argentina http://top40-charts.com/chart.php?cid=3; Austria - http://austriancharts.at/weekchart.asp?cat=s; Australia http://www.austchartbook.com.au/; Belgium - http://www.ultratop.be/en/ultratop.asp; Brazil http://www.hot100brasil.com/timemachinemain.html; Canada http://www.1050chum.com/index_chumcharts.aspx?chart=1 and http://www.muchmusic.com/tv/countdown/index.aspx?CountdownDate=4/16/2009; Chile - http://www.top40charts.com; Denmark - http://www.dr.dk/p3/tjeklisten/; Finland - http://finnishcharts.com/index.asp; France http://lescharts.com/weekchart.asp?cat=s ; Germany - http://ki.informatik.uniwuerzburg.de/ topsi/deutop20.html\#thisyear; Italy - http://www.hitparadeitalia.it/hp_weeks/index.html; Japan http://top40-charts.com/chart.php?cid=16; Netherlands - http://dutchcharts.nl/weekchart.asp?cat=s ; New Zealand http://charts.org.nz/index.asp ; Norway - http://norwegiancharts.com/weekchart.asp?cat=s ; Portugal - http://top40charts.com/chart.php?cid=20; Spain - http://top40-charts.com/chart.php?cid=21; Sweden -
} 
frequencies into comparable annual data. Tables 2 and 3 describe the underlying data's frequency (e.g. weekly or monthly) and the length of the periodic music charts.

Although ours is a sample of convenience, we have tried to find multiple countries speaking each language (e.g. Brazil and Portugal; France and Belgium; Spain, Chile, and Argentina; Germany, Austria and Switzerland) so that we can distinguish effects of distance and common language on trade. We have 10 countries continuously since the mid 1960s (or earlier): Australia, Brazil, Canada, Italy, the Netherlands, Norway, the UK, and US. We have another four with data since at least the mid 1970s: Switzerland, Belgium, New Zealand, and Sweden. France's chart data are available since 1984. Our dataset picks up two more beginning in the mid-1990s: Denmark and Finland. Finally, it expands by five countries beginning in the early 2000s: Argentina, Japan, Portugal, Spain, and Chile. Overall, countries included in our sample correspond to approximately 98\% of the $\$ 34$ billion in revenues raised with recorded music in 2003. Descriptive results and gravity equations presented in this paper are robust to the exclusion of countries that only appear in the sample after 1970 or 1980 (see sections III and V).

To make the data usable, we first needed to clean the artist names so that they are the same in each country. We accomplished this through tedious visual inspection. We also needed to determine the nationality of each artist. To this end we undertook a laborious process of searching various sources (including music encyclopedias, allmusic.com, and Wikipedia) to determine the nationality of each artist. A nationality is defined in three possible ways, in order of importance: 1) the country of the first record; 2) the country of birth; 3) country where the artist was most popular. Of the chart entries in our final sample, $34 \%, 48 \%$, and $1 \%$ used criteria 1, 2 and 3, respectively. ${ }^{15}$ This process allows us to attach nationalities to the vast majority (82\%) of the artist entries appearing in the sample. Additionally, we mechanically assign an artist's nationality to his or her chart country if that is the only country in which an artist appears

http://www.swedishcharts.com/index.asp; Switzerland - http://hitparade.ch/index.asp; United Kingdom http://www.chartstats.com/; United States - http://www.billboard.biz/bbbiz/index.jsp.

${ }^{15}$ For the sub-sample of entries with known country of first record and known country of origin, these two criteria have a similar nationality for $92 \%$ of the artists. 
on the charts (15\% of chart entries use this assignment). We were unable to find or assign nationalities to the remaining $3 \%$ of entries. ${ }^{16}$

While we would like to observe sales, our data are instead ordered chart rankings. These rankings are based largely on sales, although they are also based on part on radio airplay. ${ }^{17}$ Although we could calculate national repertoire market shares based on, say, the share of US top-100 songs by artists from France, this approach is potentially misleading. It is clearly not the case that a number-20 song contributes as much to sales as a number-one song. We can improve on equal weighting by translating chart positions into indices based on some information about the distribution of sales. There is by now an established empirical tradition of translating sales ranks into (pseudo) sales data, necessitated by the difficulty - which we share - of not observing sales quantities directly. For example Chevalier and Goolsbee (2003) and Brynjolffson, Hu, and Smith (BHS, 2003) find that sales of online books obey the " $80-20$ rule"18 and are well described by the Pareto distribution. This can be described by a relationship between log sales and the log sales rank. With fragmentary data on sales and ranks, the above authors have explored regressions of the form: $\log ($ sales $)=\alpha+\beta \log ($ rank $)+\epsilon$, where $\alpha$ and $\beta$ are coefficients, and $\varepsilon$ is an error term. Chevalier and Goolsbee find a coefficient of -0.855 for books, while BHS report -0.871 . We follow this approach, converting ranks into sales indices, using $\beta=-1 .{ }^{19}$ To this end we create a sales index that is the reciprocal of the sales ranking. That is, if a song is number 5 on a national chart in a given week, we describe its sales as $(1 / 5)^{\text {th }}$ as high as the number-one song, and so on.

In addition to giving differently-ranked songs more appropriate roles in sales, the use of this index also helps to deal with charts of different length and frequency across time and place.

\footnotetext{
${ }^{16}$ In this version of the paper we only used the nationality of the first artist listed in a chart. About $9 \%$ of the charts have at least two artists, and these two artists have identical nationality in $70 \%$ of the cases.

${ }^{17}$ Chart methodologies have changed over time with the changing role of singles. Since 1991, the Billboard Hot 100 chart has relied on a combination of sales data from Soundscan (which mechanically monitors music sales) and radio airplay data from Broadcast Data Services (which mechanically monitors airplay) rather than manual reports from radio stations and record stores. Prior to September 1995, songs could enter the chart based on airplay alone; afterwards, entering the chart required both airplay and sales. In December 1998 the methodology changed to allow songs to enter the chart based on airplay alone, allowing songs never released as singles to enter the chart. Beginning in 2005, Billboard allowed paid digital downloads to enter the chart regardless of airplay. See http://en.wikipedia.org/wiki/Billboard_charts\#Methodology_of_its_charts, accessed February 9, 2010

${ }^{18}$ That is, 20 percent of the products account for 80 percent of total sales.

${ }^{19}$ We were able to collect weekly data on recent rankings and actual sales of records for South Korea from 2001 to 2008 from the Music Industry Association of Korea in order to test such prediction. We estimated $\beta$ coefficients that ranged from -.9 to -1.1, and our preferred data and specification resulted in a coefficient of -1.03.
} 
For example, we have top-20 weekly charts for many of our country-years and top-50 weekly charts for others. If sales follow this rule, then the top 20 account for 69 percent of the sales of the top 100, and the top 50 account for 87 percent of the sales of the top 100 in that week. Whatever the underlying (weekly or monthly, etc.) chart lengths, we aggregate each artist's sales index in a chart country to the annual level, creating an annual sales index. Each country-year has at least 100 entries, so the Pareto distribution implies that a very small share of sales is omitted in our calculation of market shares. We explore the effects of different weighting schemes in section VI, and find that our main results do not depend on our choice of a particular weighting scheme.

While this translation of rank into a sales index gives us a method for calculating, say, the market share of French artists in Belgium, we also want to calculate the share of French artists in the world market (which, for us, is the sample countries). This calculation requires measures of market size - total music sales - in each of the sample countries. For years since 2003 we have direct measures of music sales in the sample countries, from the International Federation of the Phonographic Industry (IFPI). We have national GDP (from the Penn World Tables) back to the beginning of the sample. Appendix Table 1 shows IFPI and GDP shares for all countries in our sample in 2003. With the exception of Japan and England (with higher shares of music consumption than GDP shares) and Brazil (with lower share of music consumption than GDP share), all other countries in our sample have music consumption shares similar to GDP shares. We also run a regression of log IFPI on log GDP for the countries in our sample from 2003 to 2007 to gauge the relationship between both measures. The estimated coefficient of log GDP is 0.97 with standard error 0.054 .

In practice, if $s_{i}^{F}$ is the French artist market share in country $i$, and $m_{i}$ is the size of the music market in country $i$ - which we operationalize as either IFPI music sales or GDP - then the world market share for French repertoire is:

$$
\text { (3) } s^{F}=\frac{\sum_{i}^{N} s_{i}^{F} m_{i}}{\sum_{i}^{N} m_{i}} \text {, }
$$

where we have omitted time subscripts. 


\section{Empirical Results}

Our empirical inquiry proceeds in three steps. First, we descriptively examine patterns of contemporary trade in music. Second, we ask how these patterns have changed over the past half century. Third, we turn to regression models, such as gravity equations, to document these relationships more systematically, and in ways that simultaneously control for a variety of factors.

\section{IV.a. Contemporary Trade in Music}

\section{i. World Sales, Trade Shares and Proportionality}

Proportionality provides a benchmark for characterizing trade in music. Under the strict proportionality view - which would prevail if countries differed in size but had identical preferences and tendencies to supply music and if trade costs were zero - each repertoire would have the same market share in each country market. That is, the French music market share would be the same in France and in Belgium; furthermore, it would equal the French share of world GDP. Moreover, each repertoire’s share of world trade would equal its share of world sales.

Table 4 provides a first glimpse at sales and trade data, with a comparison of each national repertoire's share of trade and world consumption (which includes domestic sales of local artists) compared with the respective countries' shares of “world” GDP. ${ }^{20}$ Because of measures of sales fluctuate somewhat year to year, we use a five-year period for our characterization of contemporary patterns. In particular, we choose the most recent 5-year period for which we have sales data for all countries (2003-2007). The first column shows each country's share of sample countries’ GDP, while the second column shows each national repertoire's share of world sales, and the third column shows each repertoire's share of world trade. For example, the second row of the table shows that while Australia has 2.2 percent of world GDP, its artists garner 0.6 percent of world sales. Australian music makes up 1.2 percent

\footnotetext{
${ }^{20}$ Our sample of countries accounts for almost the totality of music revenues in the world, but it only accounts for $48 \%$ of the world GDP (as of 2003). To make the GDP-shares, music-shares comparisons more appropriate, we assume that "world" GDP shares are based on the total world GDP of the 22 countries in the sample.
} 
of world music trade. The United States leads the world consumption and trade of music - 52\% and $48 \%$ respectively - but it also has the largest share of GDP - 39\%.

To better visualize the discrepancies between sales and GDP shares, Figures 1 and 2 depict the respective relationships between log GDP shares and the repertoires' log world sales shares and log trade shares graphically. In each figure the solid line represents proportionality: the line is upward sloping because the repertoires of larger countries would be expected to occupy larger shares of total sales or trade. Both scatters of points are upward-sloping, confirming that the repertoires of larger countries tend to have larger sales and trade shares. In the world sales figure, four repertoires - from the US, UK, Japan, and Sweden - are disproportionately large and lie above the proportionality line. Many repertoires lie below the line. Three - for Portugal, Chile, and Argentina - lie far below the line.

The scatter for trade in Figure 2 remains upward-sloping, confirming that repertoires from bigger countries occupy a larger share of trade as well as world sales, as proportionality would imply. The biggest difference between the total sales and trade figures is Japan's position. While Japanese music has a large world market share due to its home sales, it makes up a small share of trade with the other sample countries. ${ }^{21}$ In contrast, the musical repertoires of Sweden, New Zealand, and Canada occupy much larger shares of trade than sales.

While the points are not literally on the line, proportionality is not a bad first approximation. ${ }^{22}$ Using the consumption data, the repertoire with the most disproportionately large share - Sweden - has a sales share that is 59 percent above its country's world GDP share. The UK is 52 percent above proportionality with GDP, and the US is 33 percent above. Looking only at trade, six countries have disproportionately large shares of world trade: Sweden (3.2 times GDP), Canada (2.2), Finland (2), UK (1.9), New Zealand (1.4), and the US (1.2). With the exception of the UK and the US, these are not particularly large countries. The US is by far the largest, and while it does have a disproportionate share of trade, its share is only 24 percent above its GDP share.

\footnotetext{
${ }^{21}$ This difference is presumed exaggerated by our sample's inclusion of no other Asian countries. But the bias is likely to be small because of regional differences in language and culture, and because other countries in Asia represent a very small fraction of the world sales.

${ }^{22}$ Regression models do not reject proportionality at 5\% significance: a linear regression of log sales shares on log GDP shares estimates a correlation of 0.61 (s.e. 0.38), while a linear regression of log trade shares on log GDP shares has a correlation of 1.31 (s.e. 0.25 ).
} 
This leads to our first empirical observation: despite widespread concern about largecountry dominance of markets for cultural goods, country repertoires’ shares are roughly proportionate to their sizes, and the US has neither the most disproportionate share of total consumption nor trade.

\section{ii. Home Market Bias?}

The deviation between repertoire shares of world trade and world sales reflects a deviation from proportionality and, in particular, possible bias in favor of domestic products. The last column of Table 4 presents each country's domestic share (e.g. the American artists' market share in the US). Under proportionality, the domestic shares would equal each country's GDP shares. Thus, the domestic shares would be larger for larger countries. Indeed, US and Japan have the largest domestic shares (89.9\% and 86.6\%). Figure 3 depicts this relationship for all countries. The scatter is clearly upward-sloping, confirming that larger countries repertoires have higher domestic sales shares. However, every country's domestic share vastly exceeds its GDP share. $^{23}$

The repertoires furthest off the proportionality line - with the highest domestic shares relative to their roles in world GDP - include New Zealand and the Scandinavian countries. Their domestic shares average nearly 50 times their shares of world GDP. The countries with the smallest proportional home bias include the US (domestic share 2.3 times its world GDP share), Germany (4.4), and Australia (6).

Home bias is by no means unique to our cultural good context: Wei (1996) documents that an average OECD country "imported" about 2.5 times as much from itself as from an otherwise similar foreign country. Still, the contemporary evidence on home bias in popular music shows a striking deviation from proportionality reflecting a strong preference for domestic repertoires.

iii. Who Trades with Whom?

\footnotetext{
${ }^{23}$ Home bias has received substantial attention in the empirical trade literature. See, for example, Holger C. Wolf (2000), or John McCallum (1995).
} 
Although home bias leads to a clear deviation from proportionality in sales figures, it is still possible that proportionality would hold among the products traded across borders for each country. To explore this, we calculate each repertoire's share of imports in each country where it is sold. Figure 4 depicts these as bar charts showing each repertoire's share of imports in other countries. (For example, the upper left picture shows Australian music's share of imports into each destination country). Under proportionality of trade, the bars for each exporter would be of equal height everywhere they are imported. For example, French music would make up the same share of imports in both the US and Belgium.

A glance at Figure 4, which depicts the import shares in descending order, shows that such proportionality does not hold for trade. The bars for each repertoire are not of equal height. For most repertoires, their height declines quickly when ordered from largest to smallest. For example, the upper left panel shows Australian music's share in the markets where it makes up the largest share of imports. These are, in order, New Zealand, the UK, and Canada. Australian music makes up 4 percent of imports in New Zealand, but less than 3 percent in the UK and Canada. Other drop-offs are similarly quick: Canadian music makes up a third of US imports but less than a tenth of imports in the next country.

While all drop-offs are clear, three occur more slowly than others: the US, UK, and Sweden (depicted in the last three panels of Figure 4). US repertoire makes up over 80 percent of imports in Canada and Australia. US repertoire makes up over 40 percent in 16 of 22 countries and over a quarter in all sample countries.

Examining these panels gives a sense of the importance of two central factors in the empirical literature on trade in goods, geographic proximity and linguistic similarity of trading partners. Brazil's repertoire has its largest trade share in Portugal, the only other Portuguesespeaking country in the sample. France has large import shares in Belgium and Switzerland (which are nearby and partly Francophone). Germany has large shares in other Germanspeaking countries: Austria and Switzerland as well as other nearby countries, including the Netherlands and Scandinavian countries. As noted above, American and Canadian repertoires are especially popular in Canada and the US, respectively, which share both a language and a border. Spain has its most substantial trade shares in Spanish-speaking Chile and Argentina, as well as geographically adjacent Portugal. We will directly estimate the importance of both 
geography and languages in the gravity equations in Section III.3. Before that, however, we descriptively examine the historic patterns in music consumption and trade.

\section{IV.b. A Half Century of Popular Music Trade}

How have national repertoires' shares of world consumption, or world trade, evolved over the past 50 years? Figure 5 provides a first pass at this question, with each country’s share of the world market since 1960. Because we have only recent IFPI music sales data, we calculate trade figures using our rank data in conjunction with GDP data. The figure includes 16 countries with continuous data since 1984, to guarantee that composition effects are not driving recent results (although similar patterns are observed for the complete sample). Only two country shares, the US and the UK, are clearly visible. A striking pattern in this figure is what one might term, "the rise and fall of the British empire": The UK repertoire share rises from about 10 percent in 1960 to a peak of over 30 percent in the 1960s (the "British invasion”). The UK share fell to 20 percent in 1970, then rose to a peak of roughly a third of the world market in the mid-1980s (the "Second British invasion”). The UK share has fallen steadily since. Music from the US takes up the largest share of the world market, but its share fell from nearly 80 percent in 1960 to a low of 40 percent in the mid-1980s. Since then, the US share has risen fairly steadily to its current level of nearly 60 percent. Because other economies tend to be small relative to the UK and, especially, the US, their consumption shares are small.

As we saw in the contemporary evidence, repertoire shares of large economies tend to be large simply because of the size of the economies. Figure 6 reports the consumption shares divided by GDP shares. Under proportionality, countries’ indices would hover near one and would not vary much over time. In this figure, the US index is close to its proportional share, while the UK index has, for most of the period, been the highest. In the mid-1980s the UK repertoire's market share was over four times its share of GDP. At times, other repertoires have had disproportionate shares: Australia's ratio reached 3 in the late 1970s, and Sweden's ratio passed 3 in the early 1990s. Canada's ratio passed 1.5 in the late 1990s. All other countries show ratios below one.

As we saw in contemporary data, home bias causes world market shares to deviate from trade shares. For example, because the US and Japan are large markets, their consumption of 
domestic artists swells their national repertoires' shares of world sales. Concerns about globalization are arguably better documented with national repertoires’ share of trade, as opposed to total sales. Figure 7 does this, showing that for most of the period - between the mid 1960s and 1990 - UK repertoire had the highest share of world trade, around 40 percent. The UK share has declined steadily since 1990, and the US share, roughly a third for most of the period, has surpassed the UK share, reaching about 40 percent in the past 15 years.

Relative to GDP, the national repertoires that have occupied disproportionate shares of world trade over the sample period are those of the UK, Sweden, Canada, and Australia. While the US index of trade has risen over the sample period, it has been below its proportional share the entire time. Except in the early 1960s, the US index has always been below the UK index, usually far below (see Figure 8). ${ }^{24}$

Despite policymaker and popular concern over US dominance, Figures 5-8 show that increased consumer access to foreign products over the past half century has not brought about a trend systematically favoring the US repertoire, or those of large economies generally, relative to smaller economies. Moreover, despite popular fears, the US is not the most disproportionately dominant supplier to the world's popular music market. The contemporary data provided evidence of a bias in favor of domestic music in every sample country. Figure 9 summarizes worldwide home bias over time (with the share of consumption worldwide that is domestic artists). This "overall home share” fell steadily from the early 1960s until the mid-1980s. As of the mid-1980s - a few years after the introduction of a single worldwide MTV - it appeared that consumers around the world were losing interest in their domestic artists. One might at the time have viewed this as a symptom that preferences were converging across the world. However, the overall home share has rebounded steadily since the mid-1980s, reversing what might have appeared ominous in $1985 .^{25}$

\footnotetext{
${ }^{24}$ Figures 6 and 8 are normalized by GDP that also changes over time. In Appendix Figure 1 we normalize export shares by a constant IFPI from 2003. These figures are almost identical to Figure 8, indicating that actual sales are the main source of variation of exports over time.

${ }^{25}$ One caveat about growing home shares in the past two decades is that ranking methodologies could also be influencing our results. As described in Section II, Billboard charts are a function of sales of singles, albums, videos and DVDs, with weights for these items changing over time. For example, the US Billboard charts have given more weight towards radio airplay time since 1998. Additionally, starting in 2005, sales of digital music are also part of the ranking equation. Our data reveals, however, that such events did not dramatically change the levels of home consumption shares in the United States. The data is more consistent with a growing trend in home bias that started
} 
Figure 10 shows each country separately. While home shares have declined in the UK over the past quarter century, they have risen in many other countries - including the US, Sweden, Brazil, France - over the past 20 years, producing the overall increase in the home share. The rising home shares outside the UK correspond to the decline of the British repertoire’s market share.

The descriptive analysis presented above could be confounded by factors not directly modeled in those figures and tables, such as distance and language effects, and other country of origin or country of destination specific effects. We now turn to estimating the home bias, language, and distance effects in the context of the gravity model in order to separate and control for those specific factors.

\section{IV.c. Gravity Equation Evidence}

We can characterize the trade data parsimoniously - and in accordance with common empirical practice in trade - using a gravity equation (see Leamer and Levinsohn, 1995 and Disdier and Head, 2010). Generically speaking, these are regressions of the log of the trade flow between countries $i$ and $j$ on measures of the sizes of the source and destination economies, as well as the distance between the two countries and measures of cultural similarity such as whether they speak a common language. ${ }^{26}$ Because we have data on both trade flows and domestic consumption, we can treat “domestic imports” as another observation and include a variable for domestic consumption, providing an estimate of home bias.

A few additional comments are in order. First, we follow the practice of including source and origin fixed effects rather than measures of economy size (Anderson and van Wincoop, 2003). Second, measuring home bias requires a measure of the distance travelled by domestic consumption. As Wolf (2000) points out, the literature has not converged on an agreed-upon method for doing this, so we try a variety of approaches. A first approach is to treat internal imports as travelling $1 \mathrm{~km}$, so that log distance is zero for domestic imports. This approach understates domestic distance and will therefore understate the extent of home bias. Second, we

in 1985 and that has not stopped since. Of course, this does not imply new technologies do not influence home bias - in Section IV we will in fact estimate their importance to domestic shares.

${ }^{26}$ We obtain data on distance and language from http://www.macalester.edu/research/economics/page/haveman/trade.resources/tradedata.html\#Gravity, accessed February 9, 2009. 
define domestic distances to be the somewhat arbitrary 100 or 500 kilometers. Finally, following Wolf (2000), we define the domestic distance as half the distance to each country's nearest country in the sample.

We begin by using annual data, 2003-2007, based on IFPI sales. An observation is the volume of imports from each national repertoire to each country by year. Thus - suppressing time subscripts - we estimate equations of the form:

(4) $\ln \left(\right.$ trade $\left._{i j}\right)=\alpha \ln \left(\right.$ distance $\left._{i j}\right)+\beta(\text { same language })_{i j}+\delta(\text { domestic })_{i j}+\mu_{i}+\mu_{j}+\varepsilon_{i j}$, where $\ln \left(\right.$ trade $\left._{i j}\right)$ is the $\log$ of trade from country $i$ to country $j$ during a year, $\ln \left(\right.$ distance $\left._{i j}\right)$ is the log of distance (in $\mathrm{km}$ ) between countries, (same language) $)_{i j}$ is an indicator which is 1 if both countries speak the same language, (domestic) $)_{i j}$ is an indicator which is 1 for domestic consumption (when $i=j$ ), $\mu_{i}$ and $\mu_{j}$ are origin and destination fixed effects, and $\varepsilon_{i j}$ is an error. We estimate the model on annual data, and we cluster errors on country pairs to deal with nonindependence of observations across years.

Table 5 reports results. The first column includes only trade (excluding domestic consumption). The distance coefficient is -0.42 , indicating that a one percent increase in distance between trading partners reduces music trade by 0.42 percent. Trade is substantially higher if the trading partners share a language: the coefficient is 0.85 in log terms. The remainder of table also includes domestic consumption, allowing for measurement of home bias. In column (2) internal distance is $1 \mathrm{~km}$, and the home bias is small and insignificant, while the distance coefficient remains close to -0.4 , and the same-language coefficient remains close to 1 . When the internal distance is measured in the other proposed ways, the home bias becomes large, with a log coefficient between 2 and 2.5. (That is, the domestic share is about three times higher than would be expected under proportionality). The distance coefficient remains about -0.4 , and the same-language coefficient remains roughly 1. Column 6 repeats the latter regression using the GDP-based import measure for the same time period, with very similar results. This is reassuring given that we rely on the GDP-based measures for the comparisons we make over time.

The appearance of a distance effect for recorded music 2003-2007 is interesting given the small trade costs associated with recorded music since 2003. Relative to manufactured goods, 
recorded music has always had smaller trade costs. As music has become a digital product in the most recent decade, traditional trade costs have declined even further.

In a meta analysis of 1467 distance coefficients from 103 studies of goods trade, Disdier and Head (2010) find an average of 0.9 ("with 90 percent of estimates lying between 0.28 and 1.55”). Distance thus matters less with music than with typical goods, which is what one might expect given the small transport costs of recorded music. That said, literal transport costs provide only one of a number of possible interpretations of distance coefficients. Blum and Goldfarb (2006) find a distance coefficient of 1.1 for information consumed digitally over the Internet. Because transport costs are literally - or virtually - zero in their context, it seems that transport costs for cultural goods might well reflect demand (preferences for proximate products), rather than supply (transport costs). A similar interpretation may hold for the distance coefficient in our context.

Using the GDP-based import measures, we can estimate the gravity model on data back to 1960. We first estimate separate models for each decade, in Table 6. We use half the distance to the nearest country as home market distance in this table's regressions. The comparison across decades reveals some interesting patterns. First, while the distance effect was small in the 1960s, it has been larger and stable since, even as trade costs of various sorts have declined. Second, the same-language preference has remained roughly constant over time. Finally, the extent of home bias has risen sharply in the last decade.

We can document this more flexibly by pooling all years' data and interacting the home dummy with a dummy for every year in the sample. ${ }^{27}$ Figure 11 shows the evolution of the average extent of home bias over time. The home bias was between 2 and 3 in the 1960's (indicating that domestic music had an average domestic share about $\exp (2)$ and $\exp (3)$ times higher than otherwise similar foreign music), and the effect drops to approximately 1 during the 1970's and 1980's. Since the late 1990s, the home bias coefficient has risen steadily to 3, indicating a home bias of about $\exp (3){ }^{28}$ This time pattern matches the path of the overall home shares shown in Figure 9. The 95\% confidence intervals for each point estimate presented in the

\footnotetext{
${ }^{27}$ We also interact year with same language, and year with distance in the same equation, in addition to including fixed effects for year, and country of origin and destination.

${ }^{28}$ Our finding of a growing home share accords with recent trends documented elsewhere. According to European Commission (2003), "Recordings by domestic artists have risen from 58\% to 68\% of sales between 1991and 2001."
} 
same figure also show that some of the recent estimates of the home bias effects are statistically distinguishable from the trough of the home bias effect observed in the 1980's. For comparison purposes, we also plot yearly point estimates for same language and distance effects in Appendix Figure 2. Interestingly, those effects are somewhat constant over those five decades.

\section{Possible Explanations for the Increasing Home Bias}

It seems ironic that the world's consumers have become more interested in their domestic music even as they have become better able to gain access to the world's music. In this section we investigate the role of recent audiovisual policies and of the spread of new technologies on the rising home bias. We consider three factors as possible explanations of the growing home bias in the music market: the appearance of regional and country-specific music television, the growth of the Internet, and domestic airplay quotas.

\section{V.a. Mechanisms}

Prior to 1980 the main way that consumers became aware of music was through radio airplay. Beginning in 1981 MTV broadcast music videos over cable television in the US. While MTV was not allowed to operate in Canada, a Canadian firm launched a Canadian music television station, CHUM MuchMusic, in 1984. But for roughly half a decade, there was only one MTV station throughout the world, which would seem to provide a force favoring a convergence of musical consumption across the globe. Moreover, it would tend to promote whichever repertoire was being broadcast. And indeed, the early years of MTV correspond to the period when the UK repertoire gained substantial market share throughout the world.

However, beginning in 1987, MTV began to splinter regionally, creating region or country-specific channels carrying some local programming (and local music). In 1987 MTV Europe was launched, broadcasting common programming throughout Europe in English. Since then, MTV has increasingly customized programming to particular countries. ${ }^{29}$ Each of these

\footnotetext{
29 MTV Brasil launched in 1990. MTV Japan launched in 1992. The year 1995 saw the launch of MTV Netherlands. In 1997, MTV launched MTV Central, serving German-speaking countries of Europe - Germany, Austria, Switzerland, and Liechtenstein - in German. MTV Argentina launched in 1999. The network also launched MTV Italy, in Italian, MTV Australia, and MTV One for the UK (in English). MTV launched MTV
} 
channels was locally tailored in terms of both language and carriage of local artists. ${ }^{30}$ Figure 12 shows the number of country-targeted MTV channels (for the countries in our sample) over time. While MTV may have begun as a force favoring convergence in music consumption across the globe, by the year 2000 MTV appeared to be a force promoting local as well as global artists.

Since the late 1990s - when consumers began sharing music illegally on the Internet the web has supplemented the role played by traditional media (radio and television) in musical discovery. It is not clear how the web would affect trade. On one hand, the web makes music of each country available to consumers both at home and abroad, which would tend to raise trade without necessarily reducing the world shares of any particular countries. On the other hand, it is possible that the web reinforces local distribution. Web distribution may complement the local promotion of concerts, in which case it would tend to promote domestic consumption more than trade. These arguments are familiar from the debate over whether the Internet provides a complement or a substitute for physical agglomeration. Evidence in Gaspar and Glaeser (1998) and Sinai and Waldfogel (2004) suggest that communication technology (including the Internet) is, on balance, a complement for agglomeration. Figure 13 shows the time pattern of Internet adoption in our sample countries. ${ }^{31}$ Internet penetration grew rapidly from 1995 to about 2005, when it ranged from around 20 percent (in sample South American countries) to around 80 percent (in the sample's Scandinavian countries).

The promotion of domestic musical artists is of sufficient importance that many countries mandate their carriage on domestic radio. Since 1971 Canada has mandated that a certain share - now 35 percent - of music be of Canadian origin ${ }^{32}$. Since 1996, France has required 40 percent of music on the radio to be French. Australia and New Zealand also require domestic content. $^{33}$ Figure 14 documents the time pattern of the mandated domestic shares in Australia,

\footnotetext{
France and MTV Spain in 2000, along with English-language MTV Nordic for Scandinavia. MTV Chile launched in 2001. MTV launched MTV Portugal in 2003. In 2005, MTV launched separate channels for Norway (MTV Norge), Finland, Denmark, and Sweden (MTV Sverige) in their respective languages. In 2006 Austria and New Zealand got their own flavors of MTV. In 2009 MTV Switzerland appeared.

${ }^{30}$ See http://en.wikipedia.org/wiki/List_of_MTV_channels and the pages linked for information on the launch of local MTV channels (accessed January 26, 2010).

${ }^{31}$ See World Bank site http://ddp-ext.worldbank.org/ext/DDPQQ/showReport.do?method=showReport for internet data, accessed in January 2010.

${ }^{32}$ See http://www.collectionscanada.gc.ca/rpm/028020-200-e.html , accessed January 21, 2010.

33 See http://www.mca.org.au/web/content/view/104/6), Bernier (2003), and Scott (2008) for evidence on the timing of these quotas. Richardson (2008) provides a theoretical treatment.
} 
France, Canada and New Zealand along with the domestic music shares in the respective countries. Particularly in Canada, New Zealand, and France, the imposition of the domestic quota coincides with a growth in domestic share.

\section{V.b. Empirical Evidence}

All of these factors - the presence of a local or a regional MTV station, the domestic adoption of the Internet, and the presence of domestic radio quotas - may explain the growing home bias. To explore this, we regress the log home share for each country in each year on time dummies, country dummies, and dummies for music television, as well as measures of Internet penetration and quotas. Results are shown in Table 7.

All three groups of variables have positive coefficients. Domestic radio quota and Internet penetration are statistically significant. The coefficient of 1.49 on the quota variable means that an increase from 0 to 0.4 (the French case) would raise the domestic sales share by about $0.6 \log$ points. The Internet coefficient of 1.29 means that a movement from 0 to 100 percent Internet penetration at home would raise the domestic music share by 1.29 log points (roughly doubling it). The MTV coefficients are also positive but rather imprecisely estimated.

To test the validity of those results, we also estimate two falsification tests. First, we test whether those channels affected a different cultural product - movies. Second, we estimate whether the three mechanisms affect home bias five years prior to the relevant time period where we should observe an effect of MTV or Internet penetration. Columns 6 and 7 of Table 7 respectively report these estimates. While the three mechanisms have positive and generally significant coefficients in music equations, they enter the movie equations insignificantly (and with negative coefficients). ${ }^{34}$ However, the timing falsification test on column 7 casts a doubt on the potential causality of the results for MTV and Internet, while it still corroborates the effect of domestic radio quotas on the growing home bias. Even though we do not have a randomized experiment to estimate the causal impact of these new communication technologies on music

\footnotetext{
${ }^{34}$ Film data are drawn from European Commission (2003). The film data include the national box office revenue and shares of box office receipts in up to 30 European countries (as well as the US and Japan) for films from each of the US, Britain, Germany, France, Italy, and Spain. The data also include the share of receipts for domestic films from each sample country. The data are available for 1980, 1985, 1990, and then annually, 1995 -2001.
} 
consumption, we can at least infer from our regression estimates that they did not diminish the viability of domestic music. Moreover, protectionist policies aimed at increasing the domestic consumption of culture goods may have produced their expected result.

While it is off our main point, it is nevertheless interesting to explore whether the quotaincreased domestic shares translate into high shares abroad. If radio airplay stimulates sales, then it's not surprising to see that the French repertoire share increases with the French domestic quotas. But how about the French repertoire share abroad? If the quotas promote airplay of music that cannot meet a market test, the music should not fare well in countries where it is not promoted by quotas. Figure 15 shows the French share in France, as well as its major music trading partners, Belgium, Spain, and Switzerland. Visual inspection suggests, perhaps counterintuitively, that protected French repertoire passes a market test abroad, particularly in Belgium. $^{35}$

\section{Robustness Tests}

\section{VI.a. Pareto Distributed “Sales” vs. Equal-Weighted Chart Entries}

Our "sales" data derived from ranks place higher weights on chart-topping artists and therefore give a larger world consumption or trade market shares to repertoires that appear in, say, the top 10 on country charts. It is possible that some national repertoire shares vary between the top of the charts and the remainder. Our basic sales measure would understate the role of a repertoire appearing disproportionately in the "basement” of country charts.

To explore this we analyze an alternative measure that weights all entries equally, a national repertoire's share of chart entries among, say, the top 50 chart entries for each country. Table 8 shows each repertoire's share among entries among sample country charts and, within country, across ranges of chart positions for the period 2003-2007. The table shows, for

\footnotetext{
${ }^{35}$ We can explore this more systematically with a regression of log repertoire shares in destination countries on year dummies, origin-destination fixed effects and dummies for both domestically protected repertoire (whether at home or abroad) and domestically protected repertoire in its protected home market. This regression yields a coefficient of 0.39 (with a standard error of 0.11 ) on protected repertoire, and an additional $0.36(0.29)$ on protected repertoire at home. That is, following the imposition of domestic protection, a protected repertoire increases its share by a statistically and economically significant 39 percent in foreign markets. Its increase in share at home is even larger but not statistically significantly so.
} 
example, that chart entries for US repertoire made up roughly a third of total chart entries in sample countries' annual top 50s. Interestingly, the US share is virtually identical for the top and bottom of the charts. Most repertoires have similar shares among top 10 and lower-ranked entries. The UK is an exception. UK repertoire makes up 8 percent of the top 10 and almost 20 percent of the entries outside the top 50. The general similarity of repertoire shares among top 10 and lower ranges indicates that our basic measure’s heavier weighting of highly ranked entries does not exert an important influence on the results.

Equal weighting among the country top 50 charts also allows us to calculate a simple overlap measure of chart convergence. We calculate this as the ratio of the number of distinct artists appearing on any charts in a year, divided by the number of chart entries in the year (essentially the number of included countries times 50). Figure 16 illustrates this. The index declines from 1960 through the mid-1980s, as the world charts come to include fewer distinct artists per chart entry. Since the mid-1980s the index has risen steadily as world charts have featured more distinct artists per entry. ${ }^{36}$ This divergence has two causes. First, it reflects the waning of the second British Invasion of the 1980s documented above. Second, it reflects the growth in attention to home-country artists in the past decade, also documented above.

\section{VI.b. Zero Gravity Issues}

Our study faces a common challenge for gravity equations, the treatment of country pairs observed not trading in a given year. Omitting these observations from the sample will give rise to biased estimates of the distance parameter if, as is plausible, observing no trade is caused by factors similar to those that would cause little trade. For our purpose we are less concerned with bias at a point in time than with possible changes in the bias from ignoring zeroes over time. One simple strategy for dealing with the zeroes is to set the zero trade observations equal to some low value, for example the minimum import observation observed for the country (from any exporter), on the view that the true value of imports is not zero but is not observed because it falls below, say, the threshold needed to appear among the importing country's top 100. Of

\footnotetext{
${ }^{36}$ Because the number of countries included increases over time, the first figure is potentially affected by sample composition. We examined this by creating separate figures for different sets of countries: 1) the 7 with chart data since 1960, 2) the 9 with data since 1965, 3) the 13 with data since 1975, 4) the 15 with data since 1984, and 5) the 22 with data since 2001. Each of these shows the chart convergence in the mid-1980s followed by divergence since. These figures are available upon request.
} 
course, other corrections are possible, for example limited dependent variable techniques ${ }^{37}$. As a rough pass at the problem, Panel A of Table 9 reports gravity equations by decade (as in Table 6), replacing the formerly missing trade data with the minimum value of imports for each importer. The levels of various estimated parameters change: distance parameters become substantially more negative, indicating that pairs of countries with no observable trade are more like to be distant from each other. Similarly, the home bias grows larger. Of greatest interest to us, the level of home bias rises sharply in the 1990s and the 2000s, as before.

\section{VI.c. Changing Country Coverage over Time}

Because the changing home bias over time is our main result, one might be concerned that it arises spuriously because of the growth in country coverage over time. To explore this, we re-estimate the gravity equations, by decade, from Table 6, including only destination countries that have been in the sample since at least 1970. Panel B of Table 10 shows that substantive results continue to hold. In particular, the extent of home bias grows substantially in the past decade.

\section{VI.d. Genre}

While our results thus far show that US artists do not disproportionately dominate the world popular music market, the US could still be spreading its culture if artists elsewhere copy American music styles. We could explore this if we had data on the genre of each artist along with information on the national origin of each genre. Then, for example, if the spread of an indigenous American genre such as rap could reflect US dominance even if the rap sold were by, say, French or German artists. To explore this, we obtained data on the genre for every CD available for sale in the US between 1985 and 2002 from MUZE, a service providing catalog data to music retailers. Some of the categories of genre in the data set include pop \& rock, R\&B, electronic, country, gospel, reggae, spoken word, oldies, and international. ${ }^{38}$ Figure 17 plots

\footnotetext{
${ }^{37}$ See Helpman, Melitz, and Rubinstein (2008) for a theoretical model predicting both the extensive and intensive margins of trade, along with an empirical implementation that deals with zero trade.

${ }^{38}$ Several caveats apply to these data: some genre are ad hoc classifications and are not necessarily associated with a country; those categories may have a current view of genre (such as "Oldies"), or US based view (such as International), or they may change over time (Spoken word is associated with Rap and Hip-Hop recently, but it was associated with Beats in the 1960's); there is a lack of unique local categories, such as Samba from Brazil, and Fado from Portugal; the coverage is much better for US and Global artists, so budding artists in smaller countries are not represented in MUZE.
} 
markets shares of genre from 1960 to 2003. In 2003, R\&B was the leading genre with 32\% market share, followed by spoken word (19\%) and rock \& pop (18\%). Rock \& pop achieved the highest market share of the sample period, reaching close to $60 \%$ in the mid-1980s', but R\&B displaced rock \& pop as the genre leader in the mid-1990s.

By construction, our genre data are representative of the music sold in the US, but the match of genre data with music charts is quite incomplete in other countries. For example, only $6.5 \%$ of the unique French artists that appear in the French charts were assigned to a genre, and

they are usually artists that have more national or international recognition. For this selected sample of artists outside the US and the UK, we find that $42 \%$ of them have rock \& pop as the main genre, $23 \%$ are classified as International, $12 \%$ are $R \& B$, and all other genre have less than $4 \%$ participation each. To the extent that rock \& pop and R\&B were originally American styles of music, one could infer that American genres are imitated abroad; but a conclusive answer to this question awaits better data.

\section{Conclusion}

Using a new and novel dataset on trade in popular music among 22 countries over the past half century, we add to what's known about cultural trade. First, despite popular and policymaker concern over large-country dominance, we find that repertoire shares of the world market - and of world trade - are roughly proportional to countries' shares of world output. Second, despite this rough proportionality, consumers clearly prefer domestic repertoire over imported music. Third, imports favor repertoires from countries that are geographically closer and which share a language. These estimates for music - a traditional and important cultural service - resemble the patterns observed in bilateral trade of physical goods.

Fourth, despite rapid improvement in information and communication technologies over the past half century, the effects of distance and language have remained fairly constant. Fifth, perhaps surprisingly, the degree of home bias has increased sharply since the late 1990s. Sixth, we present evidence that this change occurs amid the adoption of the Internet, the regional splintering of MTV, and - in four of our countries - the growth of domestic radio airplay quotas. These results imply that concerns about technological change making music more easily 
available across places do not appear to threaten the popularity of domestic artists at home. Moreover, it indicates that countries imposing quotas or providing subsidies to local cultural industries may achieve their desired goals, as several countries have ramped up their governmental intervention in cultural markets recently, such as China, India and Brazil.

Overall, our findings suggest that concern about cultural domination by large economies - particularly the US - is misplaced for music. The US is the largest consumer and exporter of music, but relative to its GDP, the US share of world music trade is sixth behind Sweden, Canada, Finland, the UK, and New Zealand. We cannot extrapolate the same conclusion for other cultural goods, such as movies and TV programs. The production of music requires only a fraction of the fixed costs demanded in the movie industry, for example, and the distribution of movies and TV shows depend on other channels. Additional empirical research is necessary to gauge the potential effect of globalization on those goods. 


\section{References}

Anderson, James, and Eric van Wincoop, “Gravity with Gravitas: A Solution to the Border Puzzle,” American Economic Review, 93 (2003), 170-192.

Anderson, James, and Eric van Wincoop, “Trade Costs,” Journal of Economic Literature, 42 (2004), 691-751.

Bala, Venkatesh and Ngo Van Long. "International Trade and Cultural Diversity with Preference Selection,” European Journal of Political Economy, 25 (2005), 143-162.

Bernier, Ivan. "Local Content Requirements for Film, Radio, and Television as a Means of Protecting Cultural Diversity: Theory and Reality,” Université Laval, Mimeo, 2003.

Berry, Steven T., and Joel Waldfogel, “Product Quality and Market Size,” Journal of Industrial Economics, forthcoming.

Blum, Bernardo S., and Avi Goldfarb, “Does the Internet Defy the Law of Gravity?” Journal of International Economics, 70 (2006), 384-405.

Chevalier, Judith, and Austan Goolsbee, "Measuring Prices and Price Competition Online: Amazon vs. Barnes and Noble,” Quantitative Marketing and Economics I, 2 (2003), 203-222.

Cowen, Tyler. Creative Destruction: How Globalization is Changing the World Cultures (Princeton: Princeton University Press, 2002).

Disdier, Anne Celia, and Keith Head, "The Puzzling Persistence of the Distance Effect on Bilateral Trade,” The Review of Economics and Statistics, 90 (2008), 37-48.

Disdier, Anne Celia, Keith Head, and Thierry Mayer, "Exposure to Foreign Media and Changes in Cultural Traits: Evidence from Naming Patterns in France,” Journal of International Economics, 80 (2010), 226-238.

Disdier, Anne Celia, Silvio H.T. Tai, Lionel Fontagne, and Thierry Mayer, "Bilateral Trade of Cultural Goods,” Review of World Economics (Weltwirtschaftliches Archiv), Springer, vol. 145 (2010), 575-595.

European Commission, Office for Official Publications of the European Communities, "Cinema, TV, and Radio in the EU, Statistics on Audiovisual Services, Data 1980-2002,” Luxembourg, 2003.

Felbermayr, Gabriel J., and Farid Toubal, “Cultural Proximity and Trade,” European Economic Review, 54 (2010), 283-297.

Francois, P., and T. van Ypersele, “On the Protection of Cultural Goods”, Journal of International Economics, 56 (2002), 359-369. 
Gaspar, J., and Edward L. Glaeser, "Information technology and the future of cities," Journal of Urban Economics, 43 (1998), 136-156.

George, Lisa M., and Joel Waldfogel, "The New York Times and the Market for Local Newspapers,” American Economic Review, 96 (2006), 435-447.

Grasstek, Van, “Treatment of Cultural Goods and Services in International Trade Agreements”, Mimeo (2005).

Hanson, Gordon H. and Chong Xiang, "Testing the Melitz Model of Trade: An Application to U.S. Motion Picture Exports,” NBER Working Paper 14461. October 2008.

Elhanan Helpman, Marc Melitz, Yona Rubinstein, "Estimating Trade Flows: Trading Partners and Trading Volumes," Quarterly Journal of Economics, 123 (2008), 441-487.

Heston, Alan, Robert Summers, and Bettina Aten, Penn World Table Version 6.2, Center for International Comparisons of Production, Income and Prices at the University of Pennsylvania, September 2006.

Janeba, Eckhard, “International Trade and Cultural Identity,” NBER Working Paper No. 10426, 2004.

Krugman, Paul, "Increasing Returns, Monopolistic Competition, and International Trade," Journal of International Economics, 9 (1979), 469-479.

Krugman, Paul, "Scale Economies, Product Differentiation, and the Pattern of Trade," American Economic Review, 70 (1980), 950-959.

Leamer, E.E., and J. Levinsohn, 1995, “International Trade Theory: The Evidence,” in Grossman G. and K. Rogoff (eds), Handbook of International Economics Volume 3, Elsevier, North-Holland.

Marvasti, Akbar, and E. Ray Canterbery, "Cultural and Other Barriers to Motion Pictures Trade,” Economic Inquiry, 43 (2005), 39-54.

McCallum, John, "National Borders Matter: Canada-US Regional Trade Patterns," American Economic Review, 85 (1995), 615-623.

Oberholzer Gee, Felix, and Joel Waldfogel, "Strength in Numbers: Group Size and Political Mobilization,” Journal of Law \& Economics, 48 (2005), 73-91.

Oberholzer Gee, Felix, and Joel Waldfogel, "Media Markets and Localism: Does Local News en Español Boost Hispanic Voter Turnout?”, American Economic Review, forthcoming.

Oster, Emily, and Robert Jensen, “The Power of TV: Cable Television and Women’s Status in India,” NBER Working Paper No. 13305, 2007.

Reinsdorf, Marshall, and Matthew J. Slaughter, International Trade in Services and Intangibles in the Era of Globalization, (Chicago: University of Chicago Press, 2009). 
Rauch, James E., and Vitor Trindade, "Neckties in the Tropics: A Model of International Trade and Cultural Diversity,” Unpublished Paper. University of California, San Diego, May 2004.

Richardson, Martin, “Commercial Broadcasting and Local Content: Cultural Quotas, Advertising, and Public Stations,” Economic Journal, 116 (2006), 605-625.

Scott, Michael, “The Networked State: New Zealand on Air and New Zealand’s Pop Renaissance,” Popular Music, 27 (2008), 299-305.

Sinai, Todd and Joel Waldfogel, "Geography and the Internet: Is the Internet a Complement or a Substitute for Cities?” Journal of Urban Economics, 56 (2004), 1-24.

Suranovic, Steve, and Robert Winthrop, “Cultural Effects of Trade Liberalization,” George Washington University, Mimeo, 2005.

Sutton, John. Sunk Costs and Market Structure (Cambridge: MIT Press, 1991).

UNESCO Sector for Culture, "International Flows of Selected Cultural Goods and Services, 1994-2003,” UNESCO Institute for Statistics, Montreal, 2005.

United Nations, Creative Economy Report 2008, 2008.

Waterman, David. Hollywood's Road to Riches. (Cambridge: Harvard University Press, 2005).

Wei, Shang-Jin, “Intra-National versus International Trade: How Stubborn Are Nations in Global Integration?” NBER Working Paper No. 5531, April 1996.

Wolf, Holger C., “Intranational Home Bias in Trade,” Review of Economics \& Statistics, 82 (2000), 555-563. 
Table 1: Artists appearing on 18+ Charts' Top 100's Since 2001

\begin{tabular}{|c|c|c|c|c|c|c|c|c|}
\hline artist & 2001 & 2002 & 2003 & 2004 & 2005 & 2006 & 2007 & Artist nationality \\
\hline Avril Lavigne & & 19 & 19 & 20 & & & & United States \\
\hline Backstreet Boys & 18 & & & & 18 & & & United States \\
\hline Beyonce & & & 21 & & & & 18 & United States \\
\hline Black Eyed Peas & & & 18 & 19 & 20 & & & United States \\
\hline Britney Spears & 19 & & & 22 & & & & United States \\
\hline Christina Aguilera & & & 19 & & & 18 & & United States \\
\hline Destiny's Child & 18 & & & 20 & 19 & & & United States \\
\hline Dido & 18 & & & & & & & United Kingdom \\
\hline Eminem & & 21 & 21 & 19 & 18 & & & United States \\
\hline Enrique Iglesias & & 19 & & & & & & United States \\
\hline Evanescense & & & 22 & 19 & & & & United States \\
\hline Faith Hill & 18 & & & & & & & United States \\
\hline Gnarls Barkley & & & & & & 18 & & United States \\
\hline Gwen Stefani & & & & & 19 & & & United States \\
\hline Jennifer Lopez & 20 & & 19 & & 20 & & & United States \\
\hline Justin Timberlake & & & & & & 18 & & United States \\
\hline Kylie Minogue & 18 & 19 & & & & & & Australia \\
\hline Las Ketchup & & 18 & & & & & & Spain \\
\hline Madonna & & 19 & 18 & & 19 & 18 & & United States \\
\hline Mariah Carey & & & & & 18 & & & United States \\
\hline Nelly Furtado & & & & & & 19 & & Canada \\
\hline Outkast & & & & 18 & & & & United States \\
\hline $\mathrm{P} ! \mathrm{Nk}$ & & 20 & & & & 19 & & United States \\
\hline Red Hot Chili Peppers & & 19 & & & & 19 & & United States \\
\hline Rihanna & & & & & & & 18 & United States \\
\hline Robbie Williams & & 18 & & & & & & United Kingdom \\
\hline Shaggy & 18 & & & & & & & other \\
\hline Shakira & & 21 & & & & 18 & & other \\
\hline T.A.T.U. & & & 21 & & & & & other \\
\hline Usher & & & & 18 & & & & United States \\
\hline Vanessa Carlton & & 18 & & & & & & United States \\
\hline
\end{tabular}

Notes: Figures based on music chart data collected for 22 countries - Argentina, Austria, Australia, Belgium, Brazil, Canada, Chile, Denmark, Finland, France, Germany, Italy, Japan, the Netherlands, New Zealand, Norway, Portugal, Spain, Sweden, Switzerland, the UK, and the US. Our definition of nationality is based on three criteria, in order: place of first recorded album, country of origin, and most popular in a given country. Avril Lavigne, Enrique Iglesias, and Rihanna, for example, were born in Canada, Spain and Barbados, respectively, but recorded their first albums in the United States. See data section for more details about the sample. 
Table 2: Chart Frequency Availability

\begin{tabular}{|c|c|c|c|c|c|}
\hline Country & Chart Entries & Annual & Monthly & Twice monthly & Weekly \\
\hline Argentina & 5754 & & & & $2001-2007$ \\
\hline Australia & 1458 & $1960-2005$ & & & \\
\hline Austria & 55502 & & 1965-1979 & 1980-1989 & $1990-2007$ \\
\hline Belgium & 98964 & & & & 1970-2007 \\
\hline Canada & 82516 & 1960-2006 & & & \\
\hline Chile & 4319 & & & & $1960-2007$ \\
\hline Denmark & 13620 & & & & 2002-2007 \\
\hline Finland & 12243 & & & & 1994-2007 \\
\hline France & 86051 & & & & 1995-2007 \\
\hline Germany & 21441 & & & & $1984-2007$ \\
\hline Italy & 37570 & & $\begin{array}{l}\text { 1960-1964, } \\
1978-2007\end{array}$ & $1965-1970$ & 1971-1977 \\
\hline Japan & 6418 & & & & $1960-2007$ \\
\hline Netherlands & 88760 & & & & 2001-2007 \\
\hline New Zealand & 76057 & & & & $1965-2007$ \\
\hline Norway & 32113 & & & & $1975-2007$ \\
\hline Portugal & 8000 & & & & $1960-2007$ \\
\hline Spain & 6640 & & & & 2001-2007 \\
\hline Sweden & 52100 & & & & 2001-2007 \\
\hline Switzerland & 83260 & & & 1976-1993 & 1994-2007 \\
\hline United Kingdom & 175088 & & & & 1968-2007 \\
\hline United States & 249980 & & & & $1960-2007$ \\
\hline
\end{tabular}

Notes: The complete list of chart sources is available in footnote 14 . 
Table 3: Chart Length Availability

\begin{tabular}{|c|c|c|c|c|c|c|c|}
\hline & Top 10- & Top 15 & Top 20 & Top 30 & Top 40 & Top 50-75 & Top 100 \\
\hline Argentina & & & $2002-2007$ & & 2001 & & \\
\hline Australia & & & 1960-1992 & & & 1993-2005 & \\
\hline Austria & $1965-1966$ & & $1967-1984$ & $1985-1994$ & $\underline{1995}-2000$ & 2001-2007 & \\
\hline Belgium & & & & 1970-1994 & & $\underline{1995-2007}$ & \\
\hline Brazil & & & & & & & 1960-2006 \\
\hline Canada & & & & 1969-2007 & & $1960-1968$ & \\
\hline Chile & & & 2002-2007 & & & & \\
\hline Denmark & & & $1994-2007$ & & & & \\
\hline Finland & & & $1995-2007$ & & & & \\
\hline France & & & & & & 1984-1997 & 1998-2007 \\
\hline Germany & & & 1960-1976 & $1977-2007$ & & & \\
\hline Italy & $1960-1984$ & & $1985-2006$ & 2007 & & & \\
\hline Japan & & & 2001-2007 & & & & \\
\hline Netherlands & & & & & $1965-2007$ & & \\
\hline New Zealand & & & & & $\begin{array}{l}\text { 1975-1978, } \\
2005-2007\end{array}$ & 1979-2004 & \\
\hline Norway & 1960-1994 & & $1995-2007$ & & & & \\
\hline Portugal & & & 2001-2005 & & & $2006-2007$ & \\
\hline Spain & & & 2001-2007 & & & & \\
\hline Sweden & & & 1975-1990 & & 1991-1994 & 1995-2007 & \\
\hline Switzerland & 1968-1975 & 1976-1982 & & 1983-1991 & 1992 & 1993-1998 & 1999-2007 \\
\hline United Kingdom & & & & & & $\begin{array}{l}\text { 1960-1982; } \\
\text { 1992-2006 }\end{array}$ & $\frac{1983-1991}{2007}$ \\
\hline United States & & & & & & & 1960-2007 \\
\hline
\end{tabular}

Notes: The complete list of chart sources is available in footnote 14. 
Table 4: Proportionality in World Sales, World Trade, and Home Shares, 2003-2007

\begin{tabular}{lcccc}
\hline Country & $\begin{array}{c}\mathbf{( 1 )} \\
\text { \% of GDP }\end{array}$ & $\begin{array}{c}\mathbf{( 2 )} \\
\text { \% of Sales }\end{array}$ & $\begin{array}{c}\mathbf{( 3 )} \\
\text { \% of Trade }\end{array}$ & $\begin{array}{c}\mathbf{( 4 )} \\
\% \text { Home } \\
\text { Share }\end{array}$ \\
\hline Argentina & $1.7 \%$ & $0.0 \%$ & $0.0 \%$ & $30.5 \%$ \\
Australia & $2.2 \%$ & $0.6 \%$ & $1.2 \%$ & $13.4 \%$ \\
Austria & $0.9 \%$ & $0.3 \%$ & $0.7 \%$ & $9.6 \%$ \\
Belgium & $1.0 \%$ & $0.4 \%$ & $0.8 \%$ & $16.0 \%$ \\
Brazil & $5.3 \%$ & $0.6 \%$ & $0.2 \%$ & $57.4 \%$ \\
Canada & $3.5 \%$ & $3.2 \%$ & $7.7 \%$ & $31.2 \%$ \\
Chile & $0.9 \%$ & $0.0 \%$ & $0.0 \%$ & $17.9 \%$ \\
Denmark & $0.5 \%$ & $0.3 \%$ & $0.5 \%$ & $45.5 \%$ \\
Finland & $0.5 \%$ & $0.5 \%$ & $1.0 \%$ & $76.4 \%$ \\
France & $5.7 \%$ & $3.6 \%$ & $1.5 \%$ & $48.1 \%$ \\
Germany & $7.7 \%$ & $3.5 \%$ & $2.9 \%$ & $34.2 \%$ \\
Italy & $5.1 \%$ & $1.2 \%$ & $1.2 \%$ & $35.4 \%$ \\
Japan & $11.9 \%$ & $15.6 \%$ & $0.0 \%$ & $86.6 \%$ \\
Netherlands & $1.7 \%$ & $0.8 \%$ & $0.9 \%$ & $33.6 \%$ \\
New Zealand & $0.3 \%$ & $0.2 \%$ & $0.4 \%$ & $16.1 \%$ \\
Norway & $0.6 \%$ & $0.3 \%$ & $0.1 \%$ & $33.2 \%$ \\
Portugal & $0.7 \%$ & $0.0 \%$ & $0.0 \%$ & $23.7 \%$ \\
Spain & $3.7 \%$ & $0.9 \%$ & $0.4 \%$ & $42.6 \%$ \\
Sweden & $0.9 \%$ & $1.4 \%$ & $2.8 \%$ & $58.8 \%$ \\
Switzerland & $0.8 \%$ & $0.2 \%$ & $0.4 \%$ & $6.6 \%$ \\
United & & & & \\
Kingdom & $5.8 \%$ & $8.8 \%$ & $10.9 \%$ & $45.9 \%$ \\
United States & $38.6 \%$ & $51.5 \%$ & $48.0 \%$ & $89.9 \%$ \\
Other & & $4.9 \%$ & $15.1 \%$ & \\
Unknown & & $1.1 \%$ & $3.5 \%$ & \\
\hline & & & & \\
\hline
\end{tabular}

Notes: Column 1 calculates GDP percentages for each country based on the sum of GDP of the 22 countries in our sample. Data comes from Penn World Table 6.3. Column 2 calculates each country percentage of total consumption of music based on IFPI, and includes domestic consumption of music. Column 3 calculates each country share of total trade only. Column 4 calculates the share of each country's consumption that is fulfilled by domestic artists. 
Table 5: Gravity Estimates, 2003-2007

\begin{tabular}{lcccccc}
\hline & $(1)$ & $(2)$ & $(3)$ & $(4)$ & $(5)$ & $(6)$ \\
& IFPI & IFPI & IFPI & IFPI & IFPI & GDP \\
\cline { 2 - 7 } Log Distance & -0.4238 & -0.3958 & -0.3958 & -0.3958 & -0.3789 & -0.3821 \\
& $(0.0704)^{* *}$ & $(0.0711)^{* *}$ & $(0.0711)^{* *}$ & $(0.0711)^{* *}$ & $(0.0743)^{* *}$ & $(0.0745)^{* *}$ \\
Same Language & 0.8513 & 0.9988 & 0.9988 & 0.9988 & 0.9816 & 0.9724 \\
& $(0.2148)^{* *}$ & $(0.2060)^{* *}$ & $(0.2060)^{* *}$ & $(0.2060)^{* *}$ & $(0.2076)^{* *}$ & $(0.2073)^{* *}$ \\
Home Bias & & 0.2906 & 2.1134 & 2.7504 & 2.5801 & 2.583 \\
& & $(-0.5576)$ & $(0.3196)^{* *}$ & $(0.2824)^{* *}$ & $(0.3007)^{* *}$ & $(0.3002)^{* *}$ \\
Distance Measure & $\mathrm{Km}+1$ & $\mathrm{Km}+1$ & $\mathrm{Km}+100$ & $\mathrm{Km}+500$ & $\mathrm{Km}^{+}$ & $\mathrm{Km}^{+}$ \\
& & & & & nearest/2 & nearest/2 \\
Observations & & & & & & \\
R-squared & 922 & 1011 & 1011 & 1011 & 1011 & 1011 \\
\hline
\end{tabular}

Notes: Dependent variable is log imports. Columns(1)-(5) use music sales measures. Column (6) uses GDP. All regressions include source and destination country fixed effects. Robust standard errors in parentheses, clustered on country pair.

* significant at $5 \%$; ** significant at $1 \%$.

Table 6: Gravity Regressions across Decades

\begin{tabular}{lccccc}
\hline & $\mathbf{( 1 )}$ & $\mathbf{( 2 )}$ & $\mathbf{( 3 )}$ & $\mathbf{( 4 )}$ & $\mathbf{( 5 )}$ \\
\hline & $1960 \mathrm{~s}$ & $1970 \mathrm{~s}$ & $1980 \mathrm{~s}$ & $1990 \mathrm{~s}$ & Since 2000 \\
\hline Log Distance & -0.0553 & -0.2666 & -0.3332 & -0.2566 & -0.3430 \\
& $(0.1409)$ & $(0.0616)^{* *}$ & $(0.0629)^{* *}$ & $(0.0591)^{* *}$ & $(0.0636)^{* *}$ \\
Same Language & 1.0338 & 1.2720 & 0.8569 & 0.7736 & 0.8271 \\
& $(0.2667)^{* *}$ & $(0.1631)^{* *}$ & $(0.1739)^{* *}$ & $(0.1561)^{* *}$ & $(0.1790)^{* *}$ \\
Home Bias & 1.9597 & 1.0288 & 1.1194 & 1.7690 & 2.5836 \\
& $(0.4375)^{* *}$ & $(0.2509)^{* *}$ & $(0.2389)^{* *}$ & $(0.2362)^{* *}$ & $(0.2637)^{* *}$ \\
Observations & 540 & 1115 & 1366 & 1819 & 1914 \\
R-squared & 0.71 & 0.71 & 0.76 & 0.75 & 0.71 \\
\hline
\end{tabular}

Notes: Dependent variable is log imports, based on GDP. All regressions include source and destination country

fixed effects. Robust standard errors in parentheses, clustered on country pair.

* significant at $5 \%$;** significant at $1 \%$. 
Table 7: Determinants of Domestic Share in Music Consumption

\begin{tabular}{lccccccc}
\hline & $\mathbf{( 1 )}$ & $\mathbf{( 2 )}$ & $\mathbf{( 3 )}$ & $\mathbf{( 4 )}$ & $\mathbf{( 5 )}$ & $\mathbf{( 6 )}$ & $\mathbf{( 7 )}$ \\
\cline { 2 - 8 } MTV regional & 0.1335 & & & & 0.1644 & -0.0666 & 0.0977 \\
& $(0.0812)$ & & & & $(0.0850)$ & $(0.1463)$ & $(0.0955)$ \\
MTV local & & 0.1268 & & & 0.0881 & -0.1512 & 0.1027 \\
& & $(0.0799)$ & & & $(0.0838)$ & $(0.1503)$ & $(0.0918)$ \\
Domestic Radio Quota & & & 1.2699 & & 1.4863 & -1.4816 & 0.2166 \\
& & & $(0.3668)^{* *}$ & & $(0.3732)^{* *}$ & $(0.8217)$ & $(0.4373)$ \\
Internet Penetration & & & & 0.0108 & 0.0129 & -0.0167 & 0.012 \\
(per 100 people) & & & & $(0.0035)^{* *}$ & $(0.0035)^{* *}$ & $(0.0073)$ & $(0.0038)^{* *}$ \\
& & & & & & & \\
Observations & 680 & 680 & 680 & 680 & 680 & 192 & 587 \\
Number of groups (countries) & 22 & 22 & 22 & 22 & 22 & 27 & 22 \\
R-squared & 0.16 & 0.16 & 0.18 & 0.17 & 0.2 & 0.03 & 0.1 \\
\hline
\end{tabular}

Notes: Columns 1 through 5 show regressions of the log domestic share on year dummies, country fixed effects and the variables shown. The dependent variable in column 6 is log domestic share of movie consumption. Column 7 shows similar regression for the the log domestic music share in year t-5.. Robust standard errors in parentheses. An observation is a country-year.

* significant at $5 \%$; ** significant at $1 \%$. 
Table 8: National Repertoire Shares of World Chart Entries, by Chart Range, 2003-2007

\begin{tabular}{lccccc}
\hline Nationality & top 10 & next 15 & next 25 & remainder & Total \\
\hline Argentina & $1.4 \%$ & $1.5 \%$ & $1.9 \%$ & $0.3 \%$ & $1.3 \%$ \\
Australia & $1.0 \%$ & $0.9 \%$ & $1.0 \%$ & $1.4 \%$ & $1.0 \%$ \\
Austria & $0.8 \%$ & $0.7 \%$ & $0.5 \%$ & $1.2 \%$ & $0.8 \%$ \\
Belgium & $1.6 \%$ & $1.4 \%$ & $1.8 \%$ & $2.4 \%$ & $1.8 \%$ \\
Brazil & $2.9 \%$ & $2.1 \%$ & $2.9 \%$ & $0.6 \%$ & $2.1 \%$ \\
Canada & $3.4 \%$ & $3.8 \%$ & $4.1 \%$ & $2.3 \%$ & $3.4 \%$ \\
Chile & $1.2 \%$ & $0.5 \%$ & $1.4 \%$ & $0.2 \%$ & $0.8 \%$ \\
Denmark & $2.5 \%$ & $2.3 \%$ & $1.3 \%$ & $1.1 \%$ & $1.8 \%$ \\
Finland & $4.8 \%$ & $4.6 \%$ & $3.7 \%$ & $4.0 \%$ & $4.3 \%$ \\
France & $5.5 \%$ & $4.5 \%$ & $4.8 \%$ & $6.6 \%$ & $5.3 \%$ \\
Germany & $3.9 \%$ & $4.6 \%$ & $4.4 \%$ & $4.9 \%$ & $4.5 \%$ \\
Italy & $2.3 \%$ & $2.1 \%$ & $2.5 \%$ & $1.9 \%$ & $2.2 \%$ \\
Japan & $3.9 \%$ & $3.9 \%$ & $4.2 \%$ & $3.3 \%$ & $3.8 \%$ \\
Netherlands & $2.0 \%$ & $2.2 \%$ & $1.7 \%$ & $2.9 \%$ & $2.2 \%$ \\
New Zealand & $0.7 \%$ & $0.5 \%$ & $0.8 \%$ & $0.7 \%$ & $0.7 \%$ \\
Norway & $1.9 \%$ & $1.5 \%$ & $1.4 \%$ & $1.2 \%$ & $1.5 \%$ \\
Portugal & $1.1 \%$ & $1.1 \%$ & $0.8 \%$ & $0.5 \%$ & $0.9 \%$ \\
Spain & $3.2 \%$ & $3.0 \%$ & $3.5 \%$ & $1.5 \%$ & $2.8 \%$ \\
Sweden & $4.6 \%$ & $3.6 \%$ & $4.0 \%$ & $5.6 \%$ & $4.5 \%$ \\
Switzerland & $0.6 \%$ & $0.4 \%$ & $0.6 \%$ & $1.1 \%$ & $0.7 \%$ \\
United Kingdom & $7.9 \%$ & $11.4 \%$ & $12.8 \%$ & $19.7 \%$ & $13.0 \%$ \\
United States & $32.8 \%$ & $35.0 \%$ & $32.4 \%$ & $28.5 \%$ & $32.2 \%$ \\
Other & $10.1 \%$ & $6.4 \%$ & $5.4 \%$ & $3.6 \%$ & $6.4 \%$ \\
Unknown & $1.7 \%$ & $2.3 \%$ & $2.9 \%$ & $4.8 \%$ & $2.9 \%$ \\
\hline
\end{tabular}

Notes: Each column calculates the national repertoire shares of world chart entries, constraining the sample to parts of the chart availability distribution (for example, column 2 calculates shares only for all top 10 entries in each year/country), and it weights all entries equally. 
Table 9: Gravity Equations across Decades: Replacing Missing Trade Values and Restricting Sample to Countries with Data since 1970

\begin{tabular}{lccccc}
\hline & $(1)$ & $(2)$ & $(3)$ & $(4)$ & $(5)$ \\
& $1960 \mathrm{~s}$ & $1970 \mathrm{~s}$ & $1980 \mathrm{~s}$ & $1990 \mathrm{~s}$ & $2000 \mathrm{~s}$ \\
\cline { 2 - 6 } B. Replacing Missing Trade Values & & & & & \\
Log Distance & -0.1637 & -0.4355 & -0.5605 & -0.4694 & -0.6926 \\
& $(-0.1057)$ & $(0.0814)^{* *}$ & $(0.0791)^{* *}$ & $(0.0726)^{* *}$ & $(0.0719)^{* *}$ \\
Same Language & 0.5639 & 1.0509 & 0.9417 & 0.6869 & 1.1835 \\
& $(0.2333)^{*}$ & $(0.2299)^{* *}$ & $(0.2086)^{* *}$ & $(0.1626)^{* *}$ & $(0.2131)^{* *}$ \\
Home Bias & 3.2285 & 2.2802 & 2.2715 & 2.7836 & 3.1269 \\
& $(0.5907)^{* *}$ & $(0.5307)^{* *}$ & $(0.5006)^{* *}$ & $(0.4729)^{* *}$ & $(0.4546)^{* *}$ \\
Observations & 1804 & 2838 & 3190 & 3542 & 3674 \\
& & & & \\
B. Countries with data since 1970 & & & & \\
Log Distance & -0.0553 & -0.2819 & -0.3368 & -0.2238 & -0.3608 \\
& -0.1409 & $(0.0670)^{* *}$ & $(0.0808)^{* *}$ & $(0.0650)^{* *}$ & $(0.0925)^{* *}$ \\
Same Language & 1.0338 & 1.3603 & 0.875 & 0.856 & 0.7016 \\
& $(0.2667)^{* *}$ & $(0.1674)^{* *}$ & $(0.1840)^{* *}$ & $(0.1792)^{* *}$ & $(0.2138)^{* *}$ \\
Home Bias & 1.9597 & 0.9735 & 0.9456 & 1.576 & 2.0906 \\
& $(0.4375)^{* *}$ & $(0.2606)^{* *}$ & $(0.2601)^{* *}$ & $(0.2368)^{* *}$ & $(0.3007)^{* *}$ \\
Observations & 540 & 1027 & 1109 & 1325 & 1081 \\
\hline
\end{tabular}

Notes: Dependent variable is log imports, based on GDP. All regressions include source and destination country fixed effects. Robust standard errors in parentheses, clustered on country pair. In contrast to Table 7, missing trade values for a country pair are replaced with the minimum value of imports observed for an importer. Destination countries with data since 1970 included: Australia, Austria, Belgium, Brazil, Canada, Germany, Italy, Netherlands, Norway, Switzerland, United Kingdom, and United States.

* significant at $5 \%$;** significant at $1 \%$ 
Figure 1. Music Consumption Shares and GDP Shares, 2003-2007

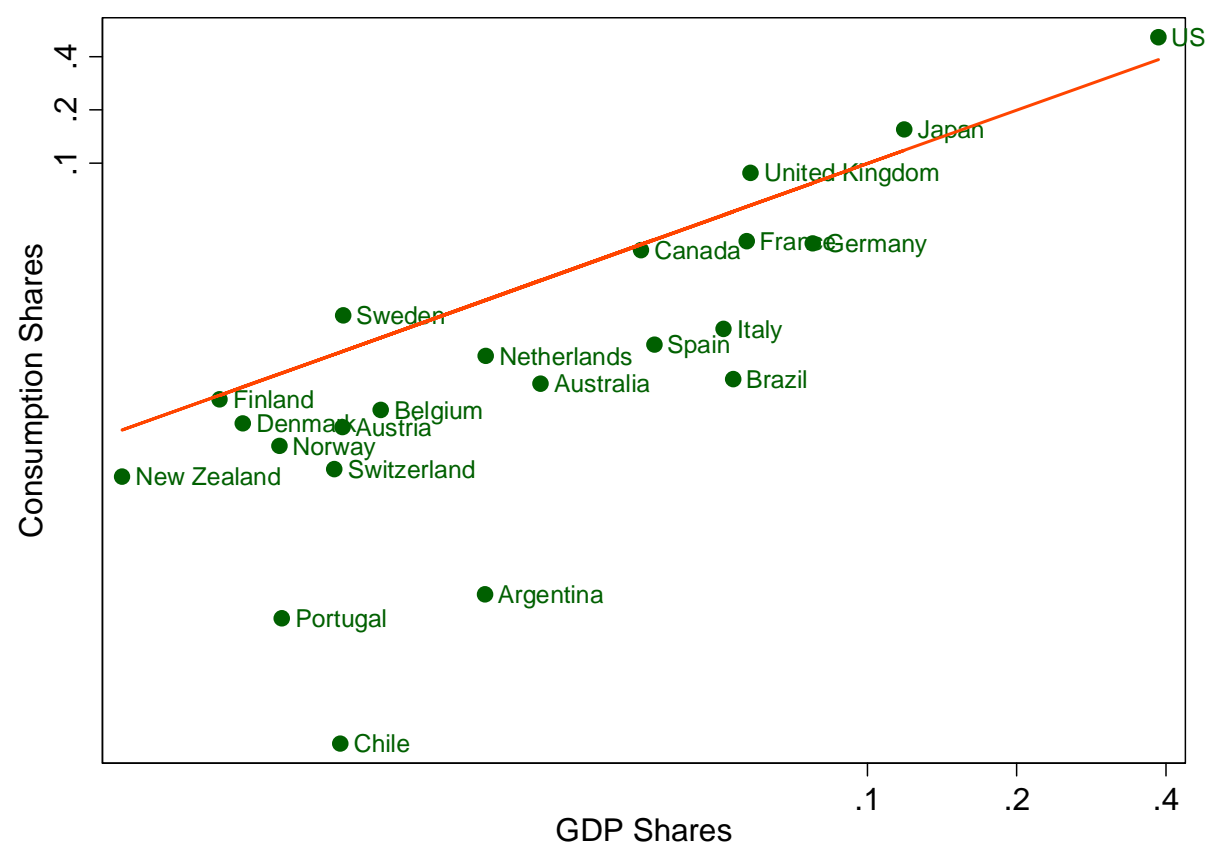

Notes: Each dot shows each country's average GDP share from 2003-2007 and the corresponding total music consumption share in the same period. Red line is the 45 degree line. Figure is plotted in log scale.

Figure 2. Music Trade Shares and GDP Shares, 2003-2007

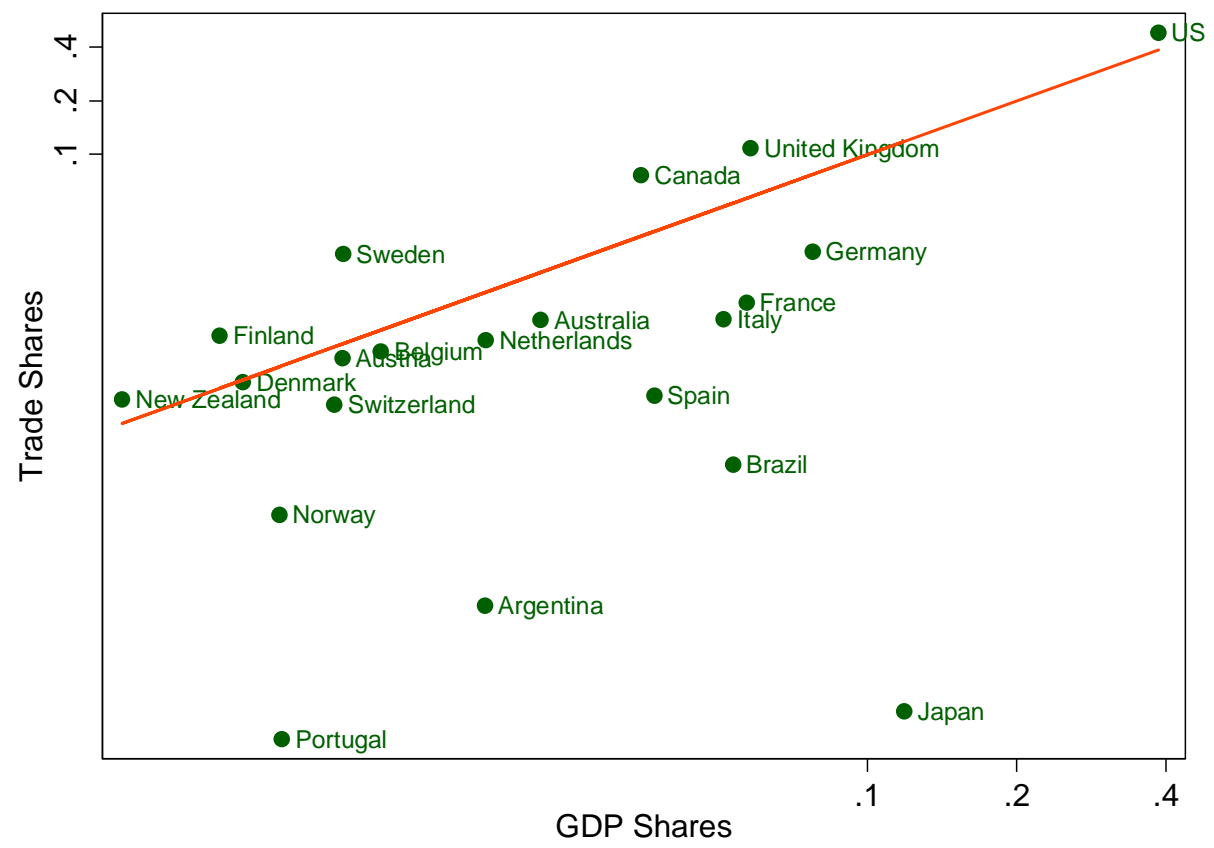

Notes: Each dot shows each country's average GDP share from 2003-2007 and the corresponding music trade share in the same period. Red line is the 45 degree line. Figure is plotted in log scale. 
Figure 3. Domestic Music Shares and GDP Shares, 2003-2007

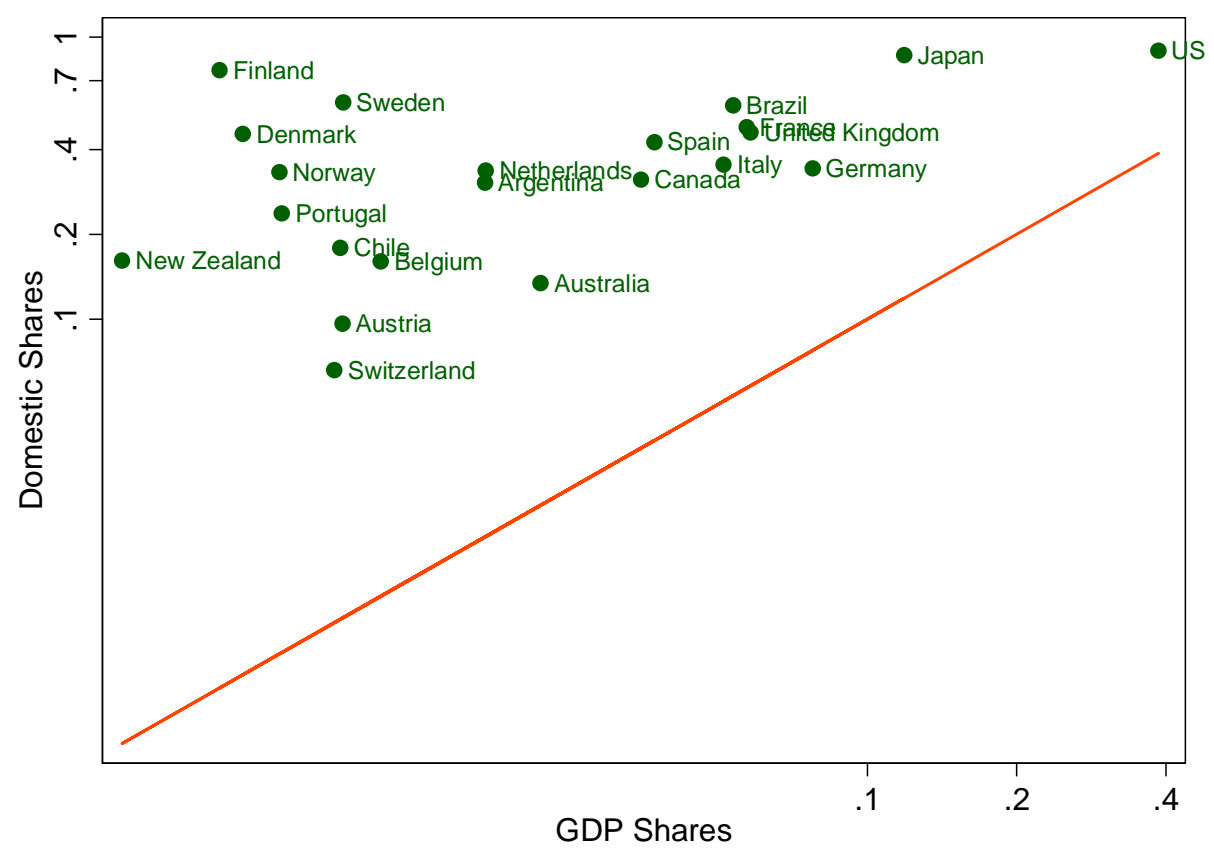

Notes: Each dot shows each country’s average GDP share from 2003-2007 and the corresponding consumption of domestic music share in the same period. Red line is the 45 degree line. Figure is plotted in log scale.

Figure 4. Repertoire Shares of Imports, 2003-2007

\section{Repertoire Shares of Imports}
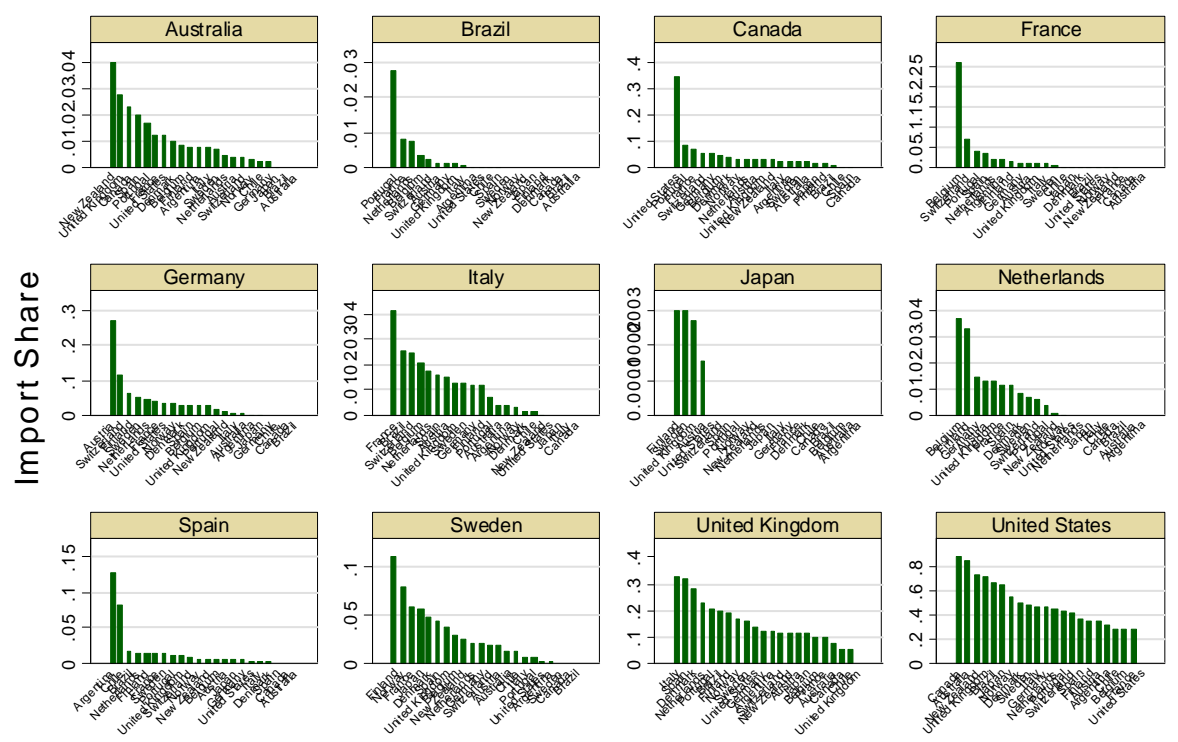

Graphs by nationality 
Figure 5. Music Consumption Shares by Country, 1960-2007

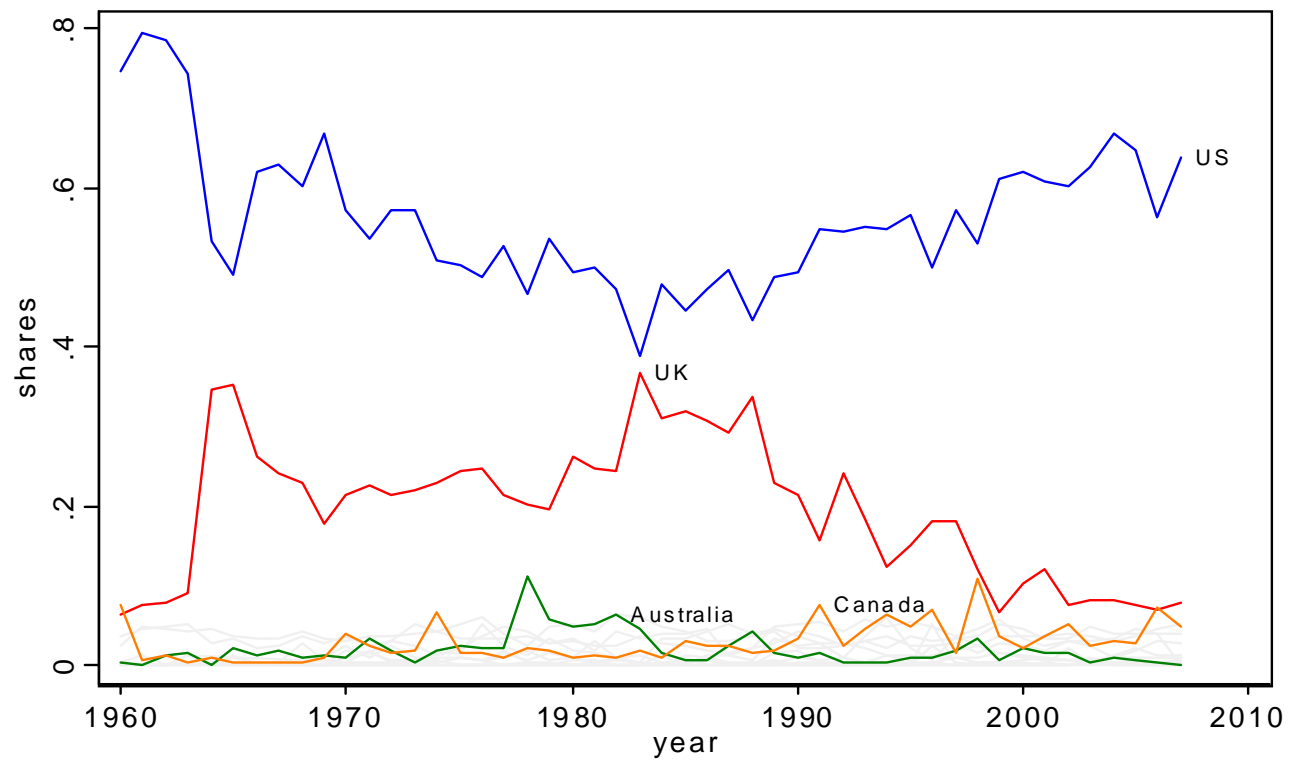

Notes: Gray lines show data for all countries that have small market shares. Consumption shares calculated according to equation (3) in the text.

Figure 6. Music Consumption Shares Divided by GDP Shares by Country, 1960-2007

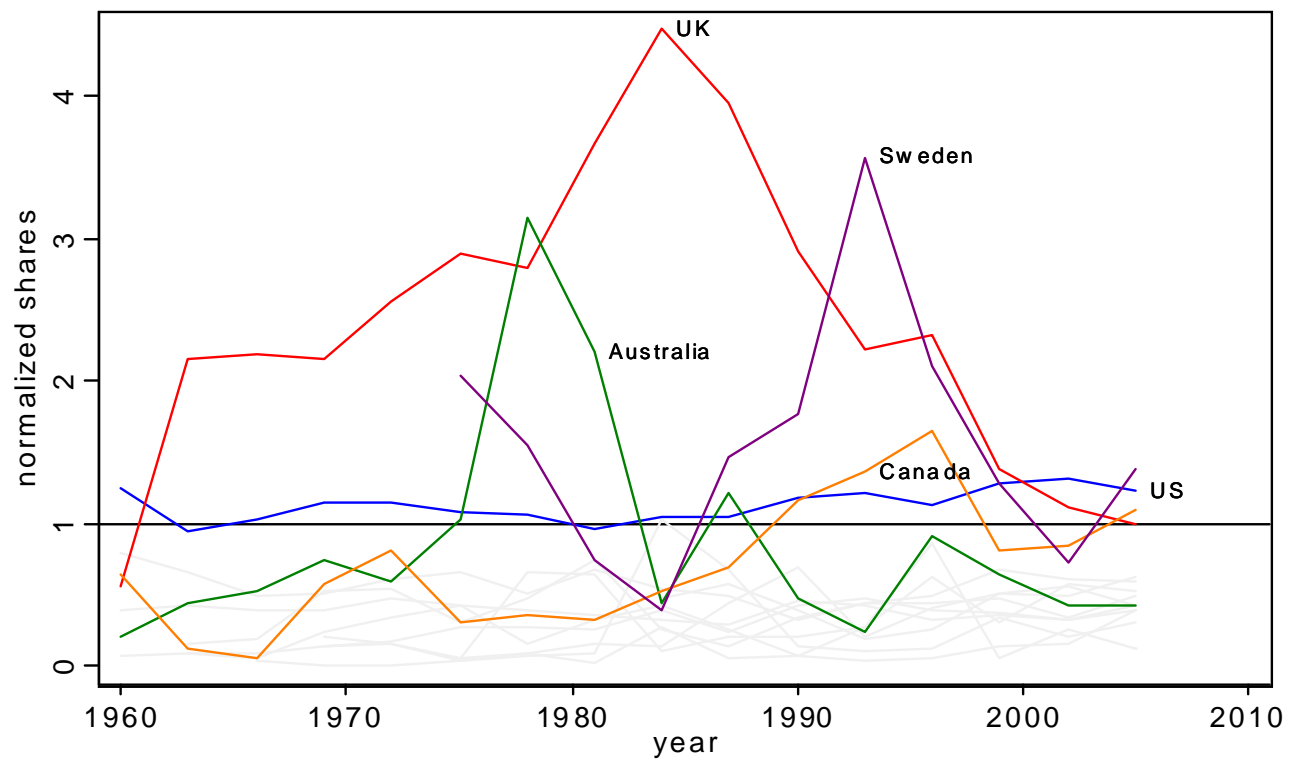

Notes: Gray lines show data for all countries that have small normalized market shares. Consumption shares calculated according to equation (3) in the text, averaged over three years, and then divided by average GDP shares over the same three years. Horizontal line of 1 represents proportionality in shares of total consumption of music. 
Figure 7. Music Export Shares by Country, 1960-2007

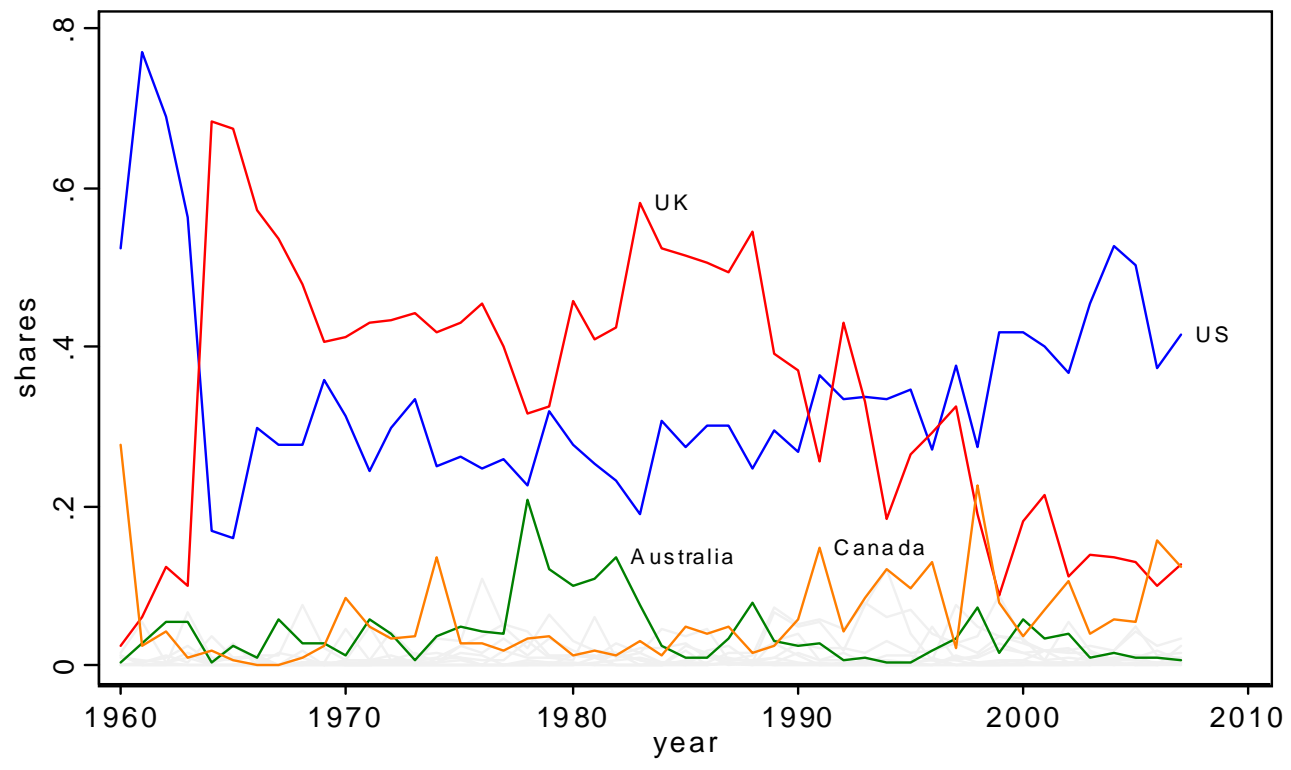

Notes: Gray lines show data for all countries that have small market shares. Export shares calculated according to equation (3) in the text, but omitting consumption of domestic music.

Figure 8. Music Export Shares Divided by GDP Shares by Country, 1960-2007

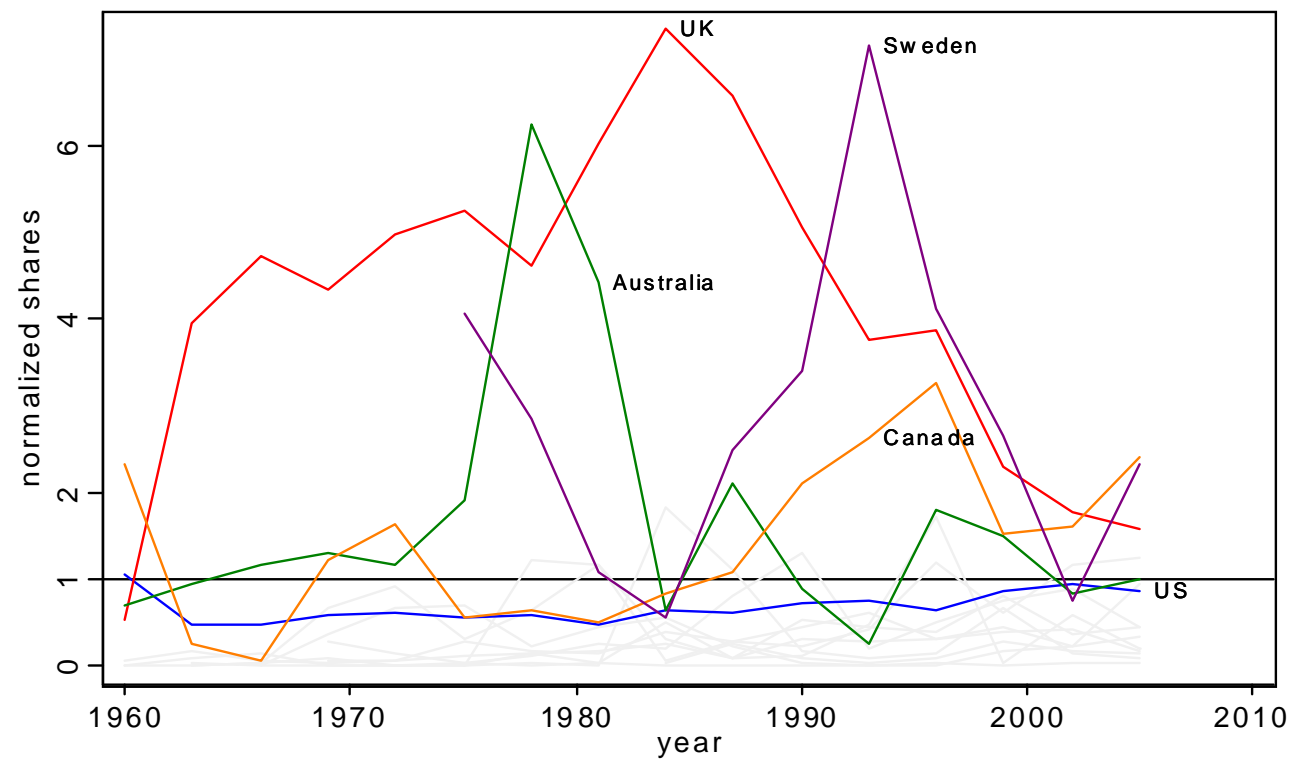

Notes: Gray lines show data for all countries that have small normalized market shares. Export shares calculated according to equation (3) in the text (but omitting consumption of domestic music), averaged over three years, and then divided by average GDP shares over the same three years. Horizontal line of 1 represents proportionality in music export shares. 
Figure 9. Overall Domestic Shares, 1960-2007

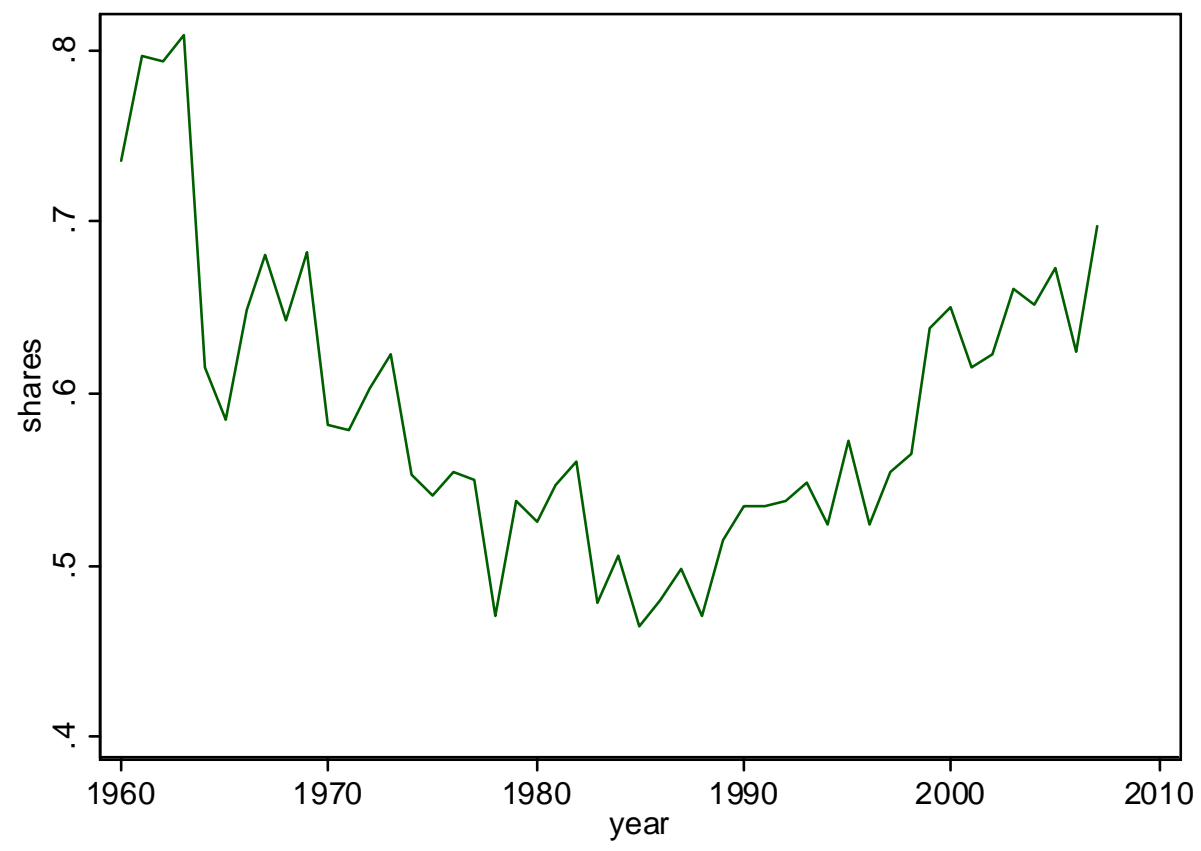

Notes: Overall domestic shares calculated as the total consumption of domestic music in all countries in a given year, divided by the total consumption of music in that year.

Figure 10. Domestic Shares By Country, 1960-2007

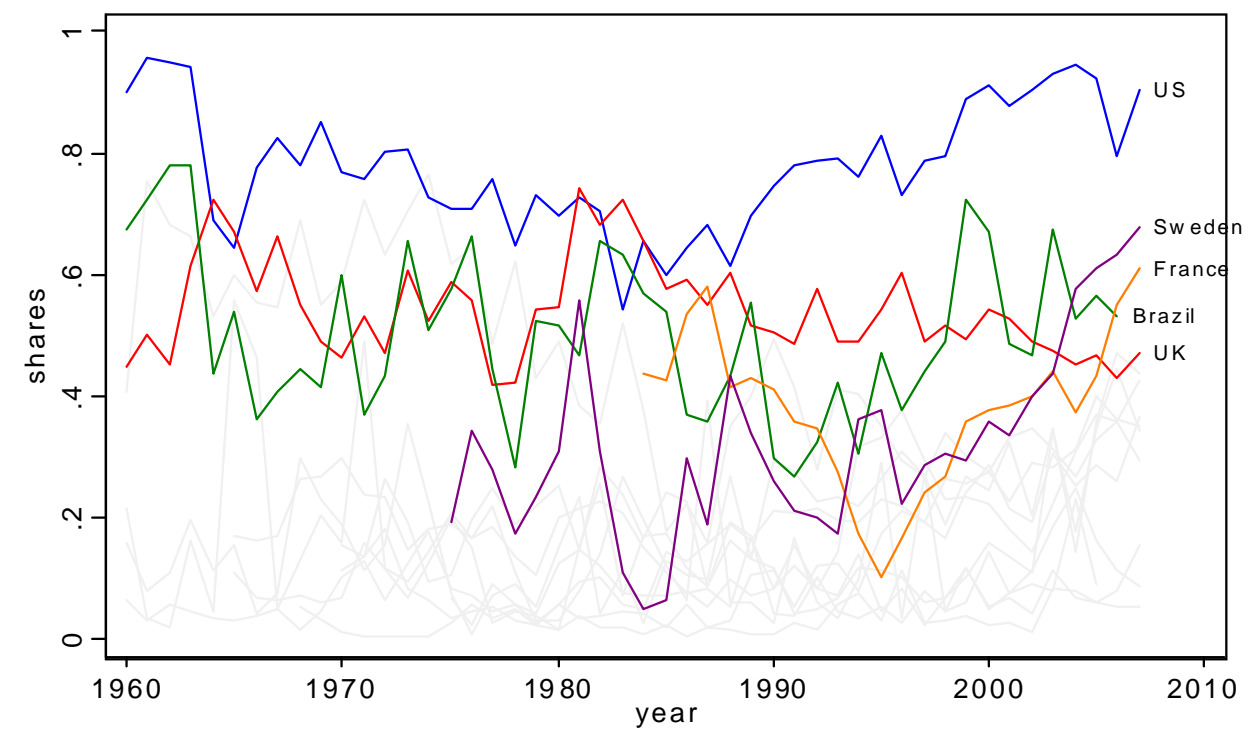

Notes: Gray lines show data for all countries that have small domestic shares. Domestic shares calculated as the total consumption of domestic music in each country in a given year, divided by the total consumption of music in each country in that year. 
Figure 11. Estimated Home Bias, 1960-2007

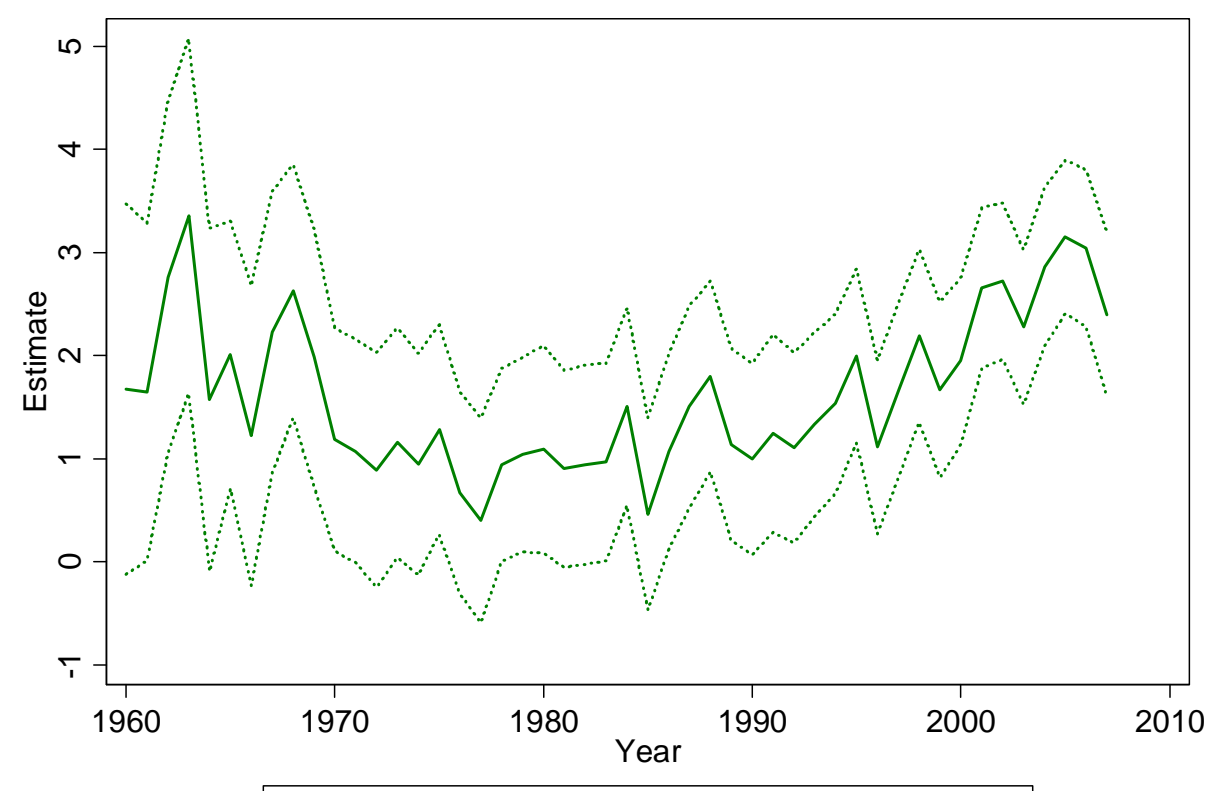

Home Bias ................ Home Bias 95\% Cl

Figure 12. Local MTV Evolution

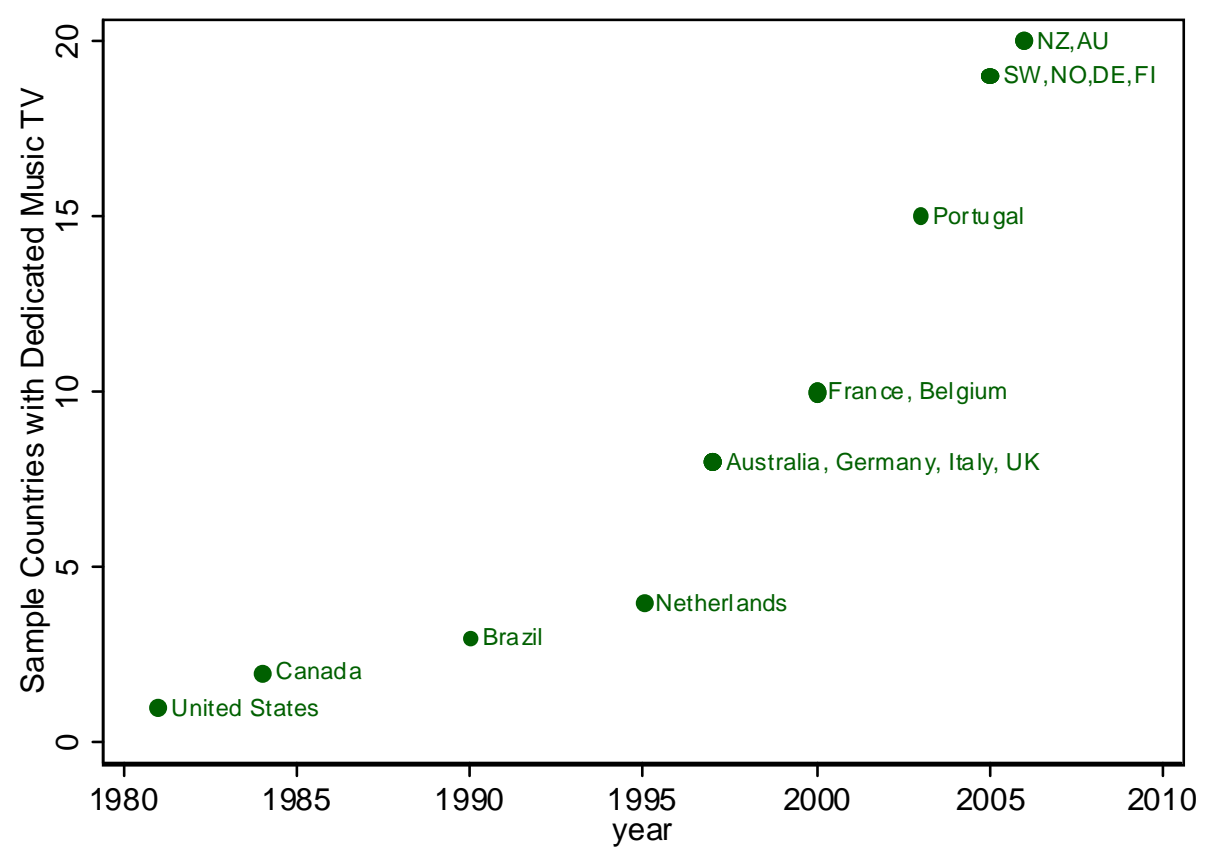

Notes: Each dot shows the first year of local MTV activities for the assigned country. Source: Wikipedia. 
Figure 13. Internet Penetration, 1990-2008

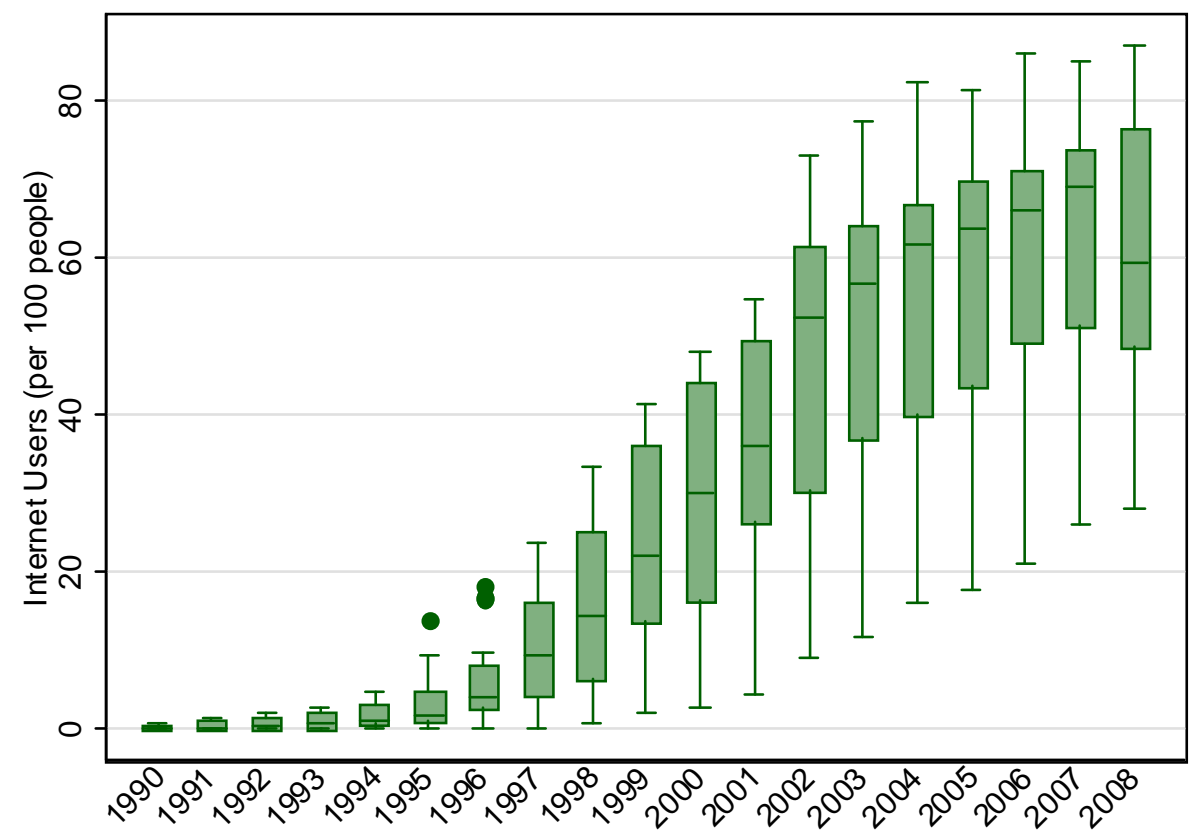

Notes: Graph shows box plots by year of internet users per 100 people for the countries in our sample.

Figure 14. Domestic Shares and Radio Quotas
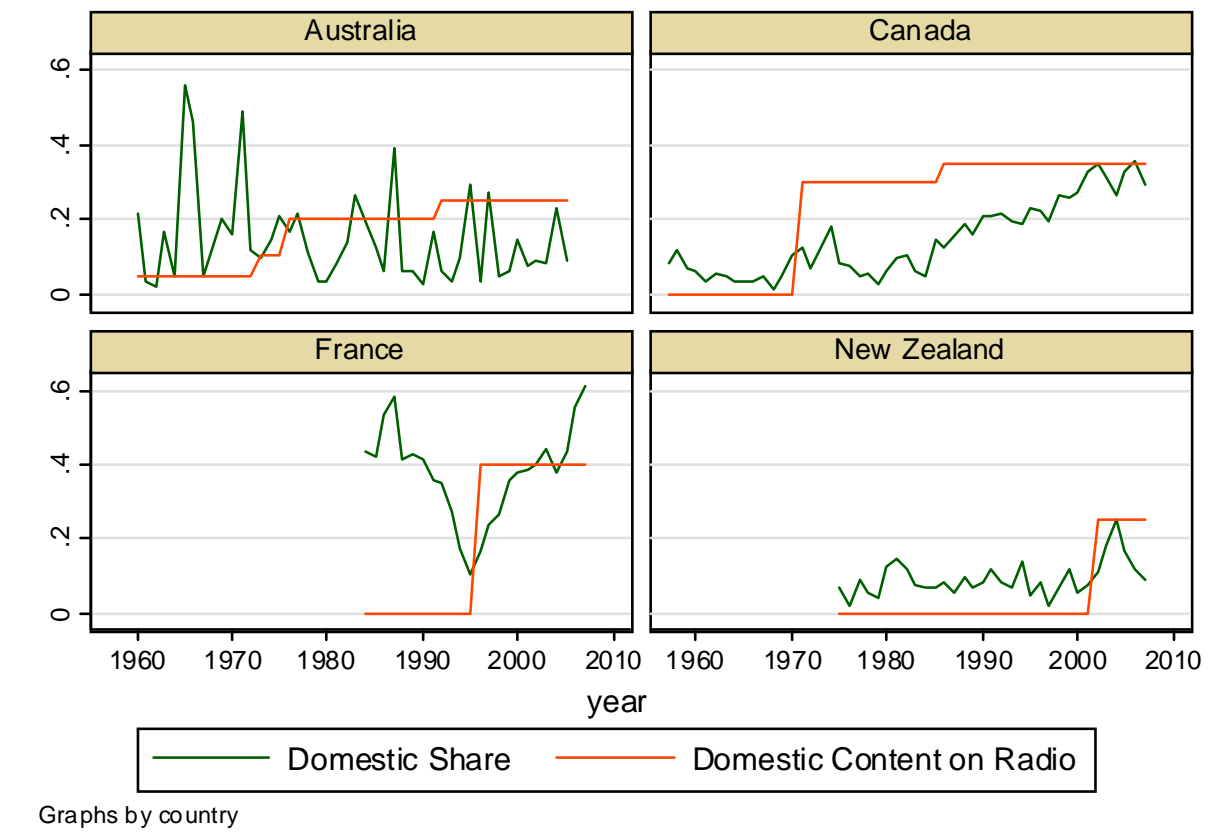

Notes: The green line in each panel shows the percentage of consumption of domestic music in the respective country. Red lines indicate the minimum percentage of radio air play devoted to domestic music according to each country's legislation. 
Figure 15: French Repertoire Share at Home and Abroad, and French Radio Quotas, 1970-2007
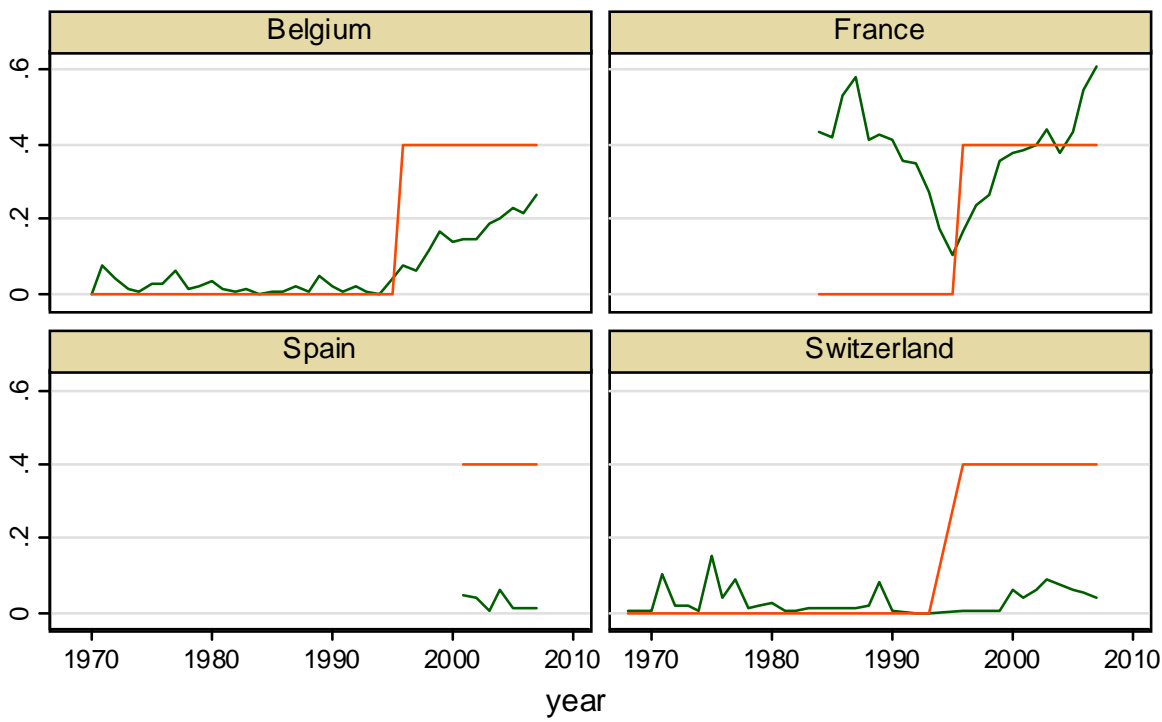

Domestic Share

\section{Domestic Content on Radio}

Graphs by country

Notes: Each panel shows the percentage of consumption of French music in the respective country. Red lines indicate the minimum percentage of radio air play devoted to French music according to the legislation in France.

Figure 16. Chart Convergence, 1960-2007

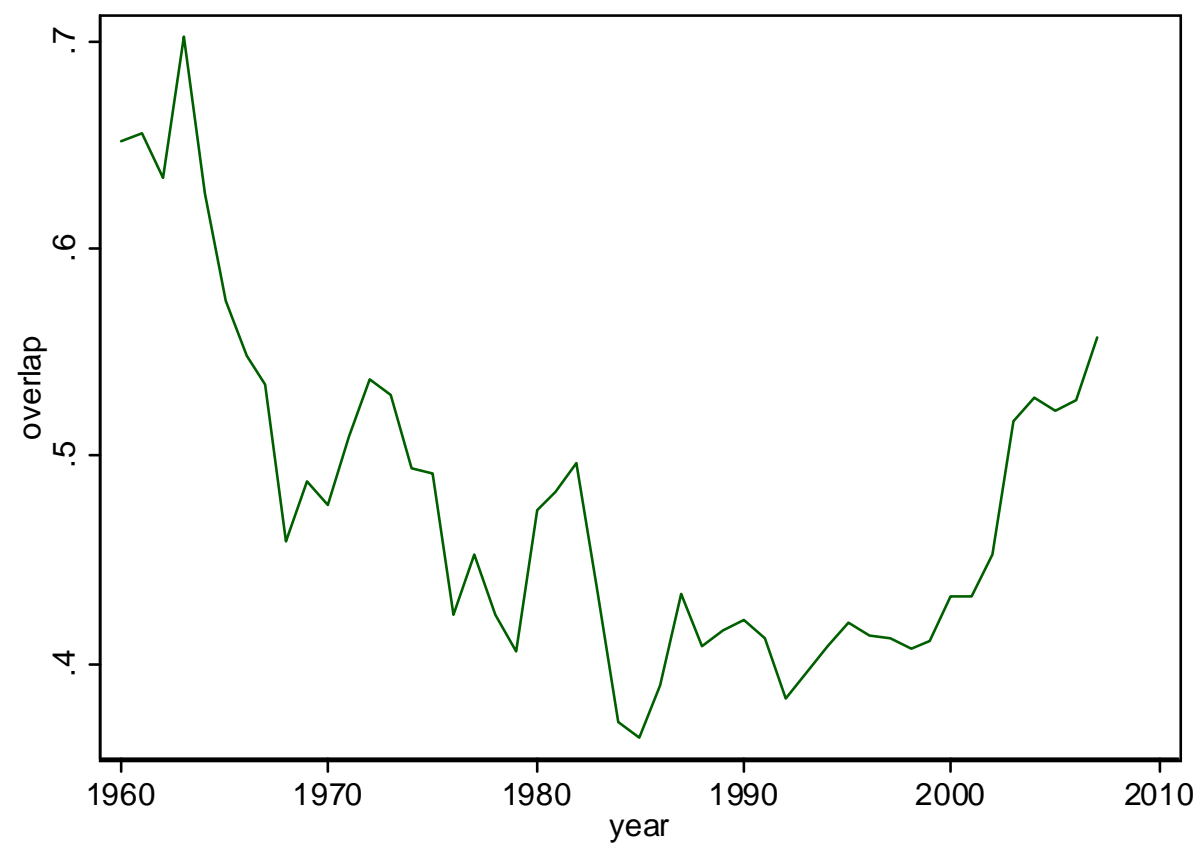

Note: the index is the ratio of (distinct artists appearing on world charts in a year)/(number of chart entries in the included countries). 
Figure 17. Genre Shares, 1960-2003

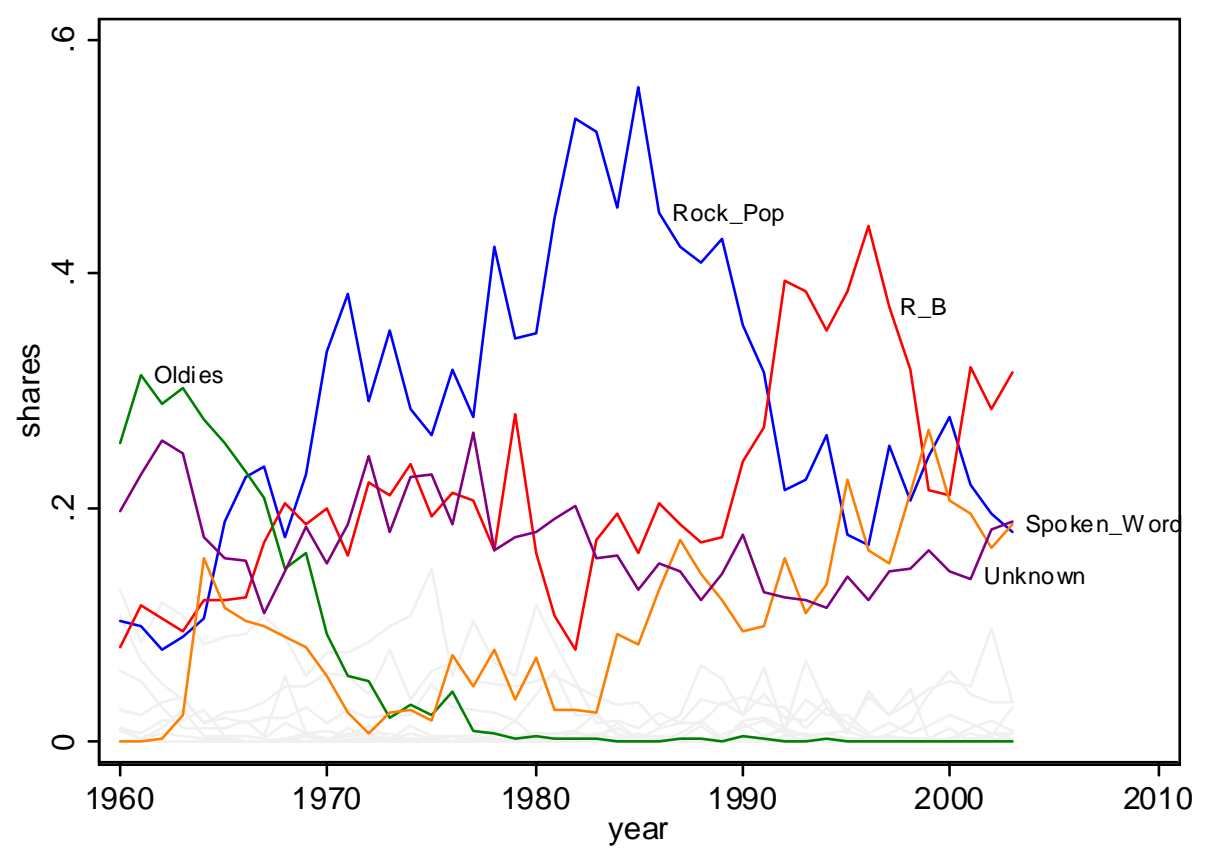

Notes: Gray lines show data for genre that have small world shares. 
Appendix Table 1. GDP and IFPI shares in 2003

\begin{tabular}{lcc}
\hline & GDP shares & IFPI shares \\
Argentina & $1.5 \%$ & $0.2 \%$ \\
Australia & $2.1 \%$ & $2.4 \%$ \\
Austria & $0.9 \%$ & $1.0 \%$ \\
Belgium & $1.0 \%$ & $0.9 \%$ \\
Brazil & $5.2 \%$ & $1.0 \%$ \\
Canada & $3.4 \%$ & $2.3 \%$ \\
Chile & $0.7 \%$ & $0.1 \%$ \\
Denmark & $0.5 \%$ & $0.6 \%$ \\
Finland & $0.5 \%$ & $0.5 \%$ \\
France & $5.8 \%$ & $7.5 \%$ \\
Germany & $8.0 \%$ & $7.2 \%$ \\
Italy & $5.3 \%$ & $2.3 \%$ \\
Japan & $12.1 \%$ & $16.9 \%$ \\
Netherlands & $1.7 \%$ & $1.8 \%$ \\
New Zealand & $0.3 \%$ & $0.4 \%$ \\
Norway & $0.6 \%$ & $0.9 \%$ \\
Portugal & $0.7 \%$ & $0.5 \%$ \\
Spain & $3.6 \%$ & $2.1 \%$ \\
Sweden & $0.9 \%$ & $1.0 \%$ \\
Switzerland & $0.8 \%$ & $0.9 \%$ \\
United Kingdom & $5.8 \%$ & $11.4 \%$ \\
United States & $38.5 \%$ & $38.0 \%$ \\
\hline
\end{tabular}


Appendix Table 2. Shares only using "born in" criteria to define nationality

\begin{tabular}{lccc}
\hline country & \% of Sales & $\%$ of Trade & $\begin{array}{c}\% \text { Home } \\
\text { Share }\end{array}$ \\
\hline Argentina & $0.0 \%$ & $0.0 \%$ & $30.5 \%$ \\
Australia & $0.6 \%$ & $1.1 \%$ & $13.4 \%$ \\
Austria & $0.3 \%$ & $0.7 \%$ & $9.6 \%$ \\
Belgium & $0.4 \%$ & $0.8 \%$ & $16.0 \%$ \\
Brazil & $0.6 \%$ & $0.2 \%$ & $57.4 \%$ \\
Canada & $3.9 \%$ & $9.3 \%$ & $34.4 \%$ \\
Chile & $0.0 \%$ & $0.0 \%$ & $18.8 \%$ \\
Denmark & $0.3 \%$ & $0.4 \%$ & $45.5 \%$ \\
Finland & $0.5 \%$ & $1.0 \%$ & $77.1 \%$ \\
France & $3.6 \%$ & $1.4 \%$ & $48.2 \%$ \\
Germany & $3.5 \%$ & $2.8 \%$ & $34.2 \%$ \\
Italy & $1.2 \%$ & $1.2 \%$ & $35.4 \%$ \\
Japan & $15.6 \%$ & $0.0 \%$ & $86.6 \%$ \\
Netherlands & $0.8 \%$ & $1.0 \%$ & $33.6 \%$ \\
New Zealand & $0.2 \%$ & $0.6 \%$ & $16.5 \%$ \\
Norway & $0.3 \%$ & $0.1 \%$ & $33.2 \%$ \\
Portugal & $0.0 \%$ & $0.0 \%$ & $23.7 \%$ \\
Spain & $1.0 \%$ & $0.7 \%$ & $42.6 \%$ \\
Sweden & $1.4 \%$ & $2.7 \%$ & $57.5 \%$ \\
Switzerland & $0.2 \%$ & $0.4 \%$ & $6.6 \%$ \\
United Kingdom & $9.0 \%$ & $11.4 \%$ & $45.8 \%$ \\
United States & $50.0 \%$ & $44.6 \%$ & $88.1 \%$ \\
other & $5.3 \%$ & $16.2 \%$ & \\
unknown & $1.1 \%$ & $3.4 \%$ & \\
\hline & & & \\
\hline
\end{tabular}


Appendix Figure 1. Export shares normalized by constant IFPI

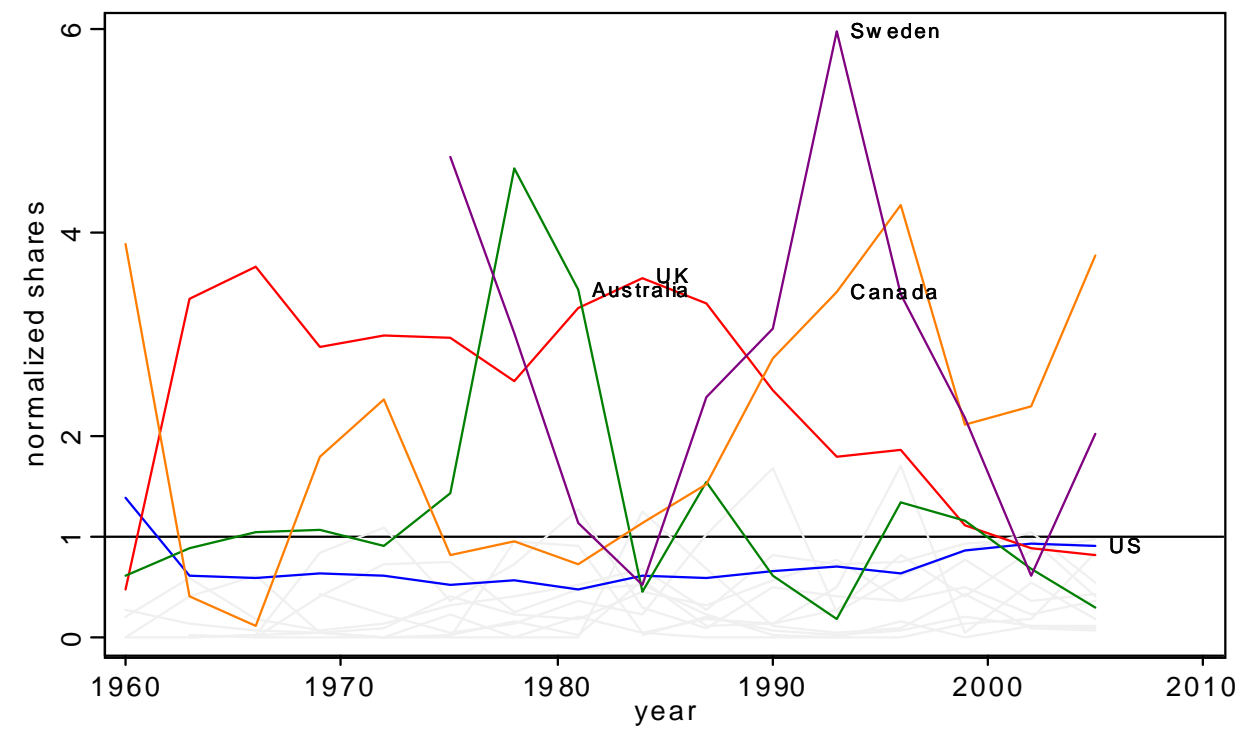

Appendix Figure 2. Estimated Distance and Same Language Effects, 1960-2007

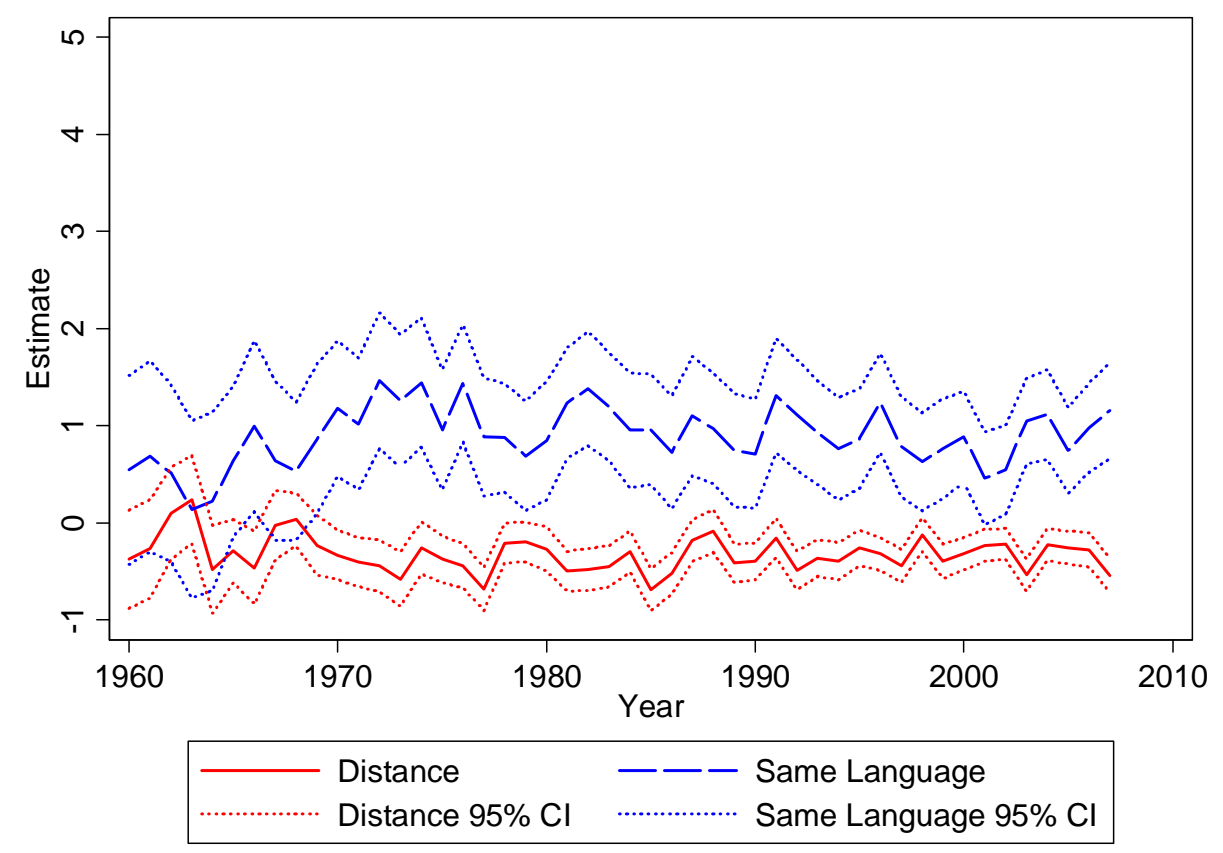

